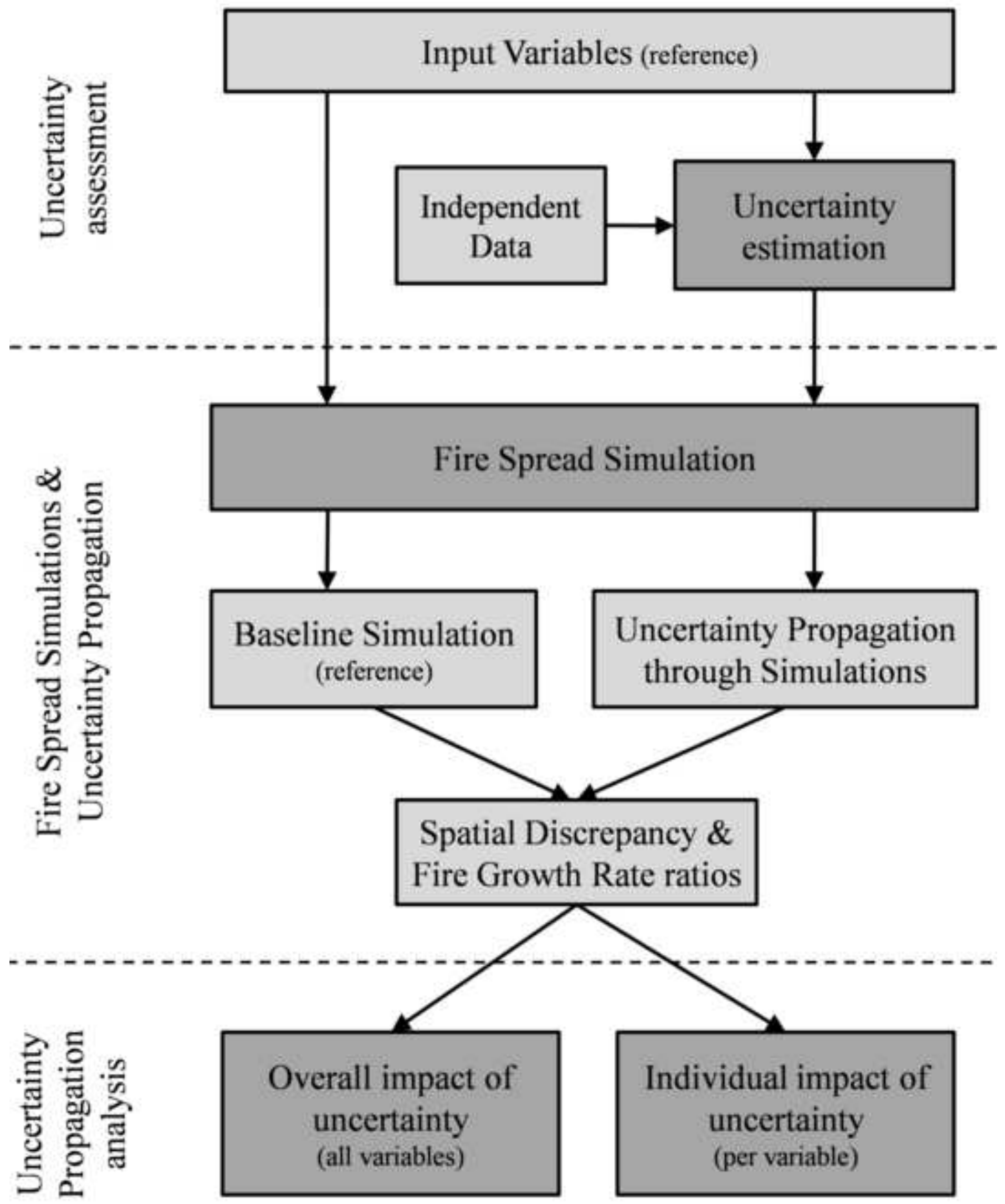




\section{Deciphering the impact of uncertainty on the accuracy of large wildfire spread simulations.}

Akli Benali $^{\mathrm{a},{ }^{*}}$, Ana R. Ervilha ${ }^{\mathrm{b}}$, Ana C.L. Sá ${ }^{\mathrm{a}}$, Paulo M. Fernandes ${ }^{\mathrm{c}}$, Renata M.S. Pinto ${ }^{\mathrm{a}}$, Ricardo

M. Trigo ${ }^{\mathrm{d}}$, José M.C. Pereira ${ }^{\mathrm{a}}$

${ }^{\text {a }}$ Centro de Estudos Florestais, Instituto Superior de Agronomia, Universidade de Lisboa, Tapada da Ajuda, Lisboa, Portugal.

${ }^{\mathrm{b}}$ LAETA, IDMEC, Instituto Superior Técnico, Universidade Lisboa, Departamento de Engenharia Mecânica, LASEF, Av. Rovisco Pais, 1, Lisboa, Portugal

${ }^{\mathrm{c}}$ Centro de Investigação e de Tecnologias Agro-Ambientais e Biológicas, Universidade de Trásos-Montes e Alto Douro, Quinta de Prados, Vila Real, Portugal

d Instituto Dom Luís, Faculdade de Ciências da Universidade de Lisboa, Campo Grande Edifício C8, Piso 3, Lisboa, Portugal

* Corresponding author.

Email: aklibenali@gmail.com (AB)

Keywords: spatial discrepancy; satellite; FARSITE; MODIS; fire behavior; hotspots 


\begin{abstract}
Predicting wildfire spread is a challenging task fraught with uncertainties. 'Perfect' predictions are unfeasible since uncertainties will always be present. Improving fire spread predictions is important to reduce its negative environmental impacts. Here, we propose to understand, characterize, and quantify the impact of uncertainty in the accuracy of fire spread predictions for very large wildfires. We frame this work from the perspective of the major problems commonly faced by fire model users, namely the necessity of accounting for uncertainty in input data to produce reliable and useful fire spread predictions. Uncertainty in input variables was propagated throughout the modeling framework and its impact was evaluated by estimating the spatial discrepancy between simulated and satellite-observed fire progression data, for eight very large wildfires in Portugal. Results showed that uncertainties in wind speed and direction, fuel model assignment and typology, location and timing of ignitions, had a major impact on prediction accuracy. We argue that uncertainties in these variables should be integrated in future fire spread simulation approaches, and provide the necessary data for any fire model user to do so.
\end{abstract}




\section{Introduction}

Wildfires have important impacts on air and water quality, ecosystem dynamics, soil properties, and are important threats to humans. Fire spread is a complex phenomenon, determined by chemical and physical processes that occur over multiple spatial and temporal scales. Interactions between fire, fuels, weather and topography, broadly determine fire spread, rate of energy release and the shape of its perimeter (Albini, 1976; Rothermel, 1972). Fire spread models have been widely used to predict the spatio-temporal patterns of fire behavior (Finney, 2004), to study the effects of fuel treatments (e.g. Cochrane et al., 2012), perform risk assessments (e.g. Salis et al., 2013), predict short-term fire behavior (e.g. Kochanski et al., 2013), and to understand the main drivers of fire behavior (e.g. Cruz et al., 2012) and of fire regimes (e.g. Fernandes et al., 2014).

Accurate fire behavior prediction remains a difficult and challenging objective to achieve, despite numerous modeling efforts. This is due to a wide range of factors such as wind and fuel variability, dynamic interactions between fire and its surrounding environment, long-range spotting and simultaneous ignitions (Alexander and Cruz, 2013b; Cruz and Alexander, 2013; Hilton et al., 2015). Additionally, computational constraints and poorly understood small-scale processes (Beven, 2002) increase the difficulty of accurately predicting fire spread. Although much progress has been made in understanding and modeling the behavior of wildland fires, our ability to produce accurate predictions has evolved very little, mainly due to the spatial and temporal variability of the phenomenon, but also due to the lack of systematic methods for model validation (Alexander and Cruz, 2013a; Alexander and Cruz, 2013b; Salvador et al., 2001).

Modeling complex environmental phenomena is fraught with uncertainties (Beven and Binley, 1992) and fire behavior is no exception. Uncertainty is intrinsically associated with lack 
of information. Knowledge uncertainty is driven by imperfect state-of-the-art scientific knowledge and results from the way natural processes are conceptualized, how processes are modeled, and data quality (see Refsgaard et al., 2007; Thompson and Calkin, 2011 for in-depth reviews).

Modeling fire behavior is intrinsically uncertain due to: i) model applicability, scope and inherent limitations; ii) limitations of current scientific knowledge; iii) inherent accuracy of model structure; iv) parametric uncertainty; v) natural variability; vi) input data reliability; and vii) skill and knowledge of the user (Albini, 1976; Alexander and Cruz, 2013b; Bachmann and Allgöwer, 2002; Beven and Binley, 1992; Cruz, 2010; Liu et al., 2015; Thompson and Calkin, 2011). Under certain conditions, input data reliability can be the dominant source of error in fire spread predictions (Alexander and Cruz, 2013b). Errors associated with wind and fuel data have been considered the most relevant (e.g. Albini, 1976). The temporal and spatial variability of wind, due to the turbulent nature of the atmospheric boundary layer (Cruz, 2010), is extremely difficult to capture and can result in large errors (Albini, 1976; Anderson et al., 2007; Bachmann and Allgöwer, 2002). Errors associated with fuel classification and parameterization (Keane and Reeves, 2012), along with the large spatial fuel variability and heterogeneity have profound impacts on predicted fire behavior (Albini, 1976; Salazar, 1985).

Cruz and Alexander (2013) noted that "the only certainty about wildland fire behavior predictions is that it is extremely unlikely that a prediction will exactly match the observed fire behavior". Consequently, it is important to better understand the nature of uncertainty, how it propagates through fire spread models and how it affects its predictions (Sullivan, 2009; Thompson and Calkin, 2011). Through realistic estimation of predictive uncertainty one can improve the accuracy of fire spread simulations and promote a better understanding of model 
capabilities (Beven, 2002), as well as provide information on the variability and reliability of fire behavior predictions that can be used to improve risk management and decision-making (Bachmann and Allgöwer, 2002; Thompson and Calkin, 2011). However, to the best of our knowledge, this topic has merited little research (Bachmann and Allgöwer, 2002; Clark et al., 2008; Salazar, 1985; Salvador et al., 2001), despite the wide use of fire spread models in recent years.

Fire behavior modeling will be truly useful when its predictions are accurate. Therefore, we frame this work considering some of the biggest challenges involved in setting up and using a fire spread modeling system. Our main objective is to understand, characterize and quantify the impact of data uncertainty on the accuracy of fire spread predictions for large wildfires. We investigate i) the overall impact of uncertainty on simulation accuracy, and ii) the response of simulation accuracy to the range of uncertainty values of each input variable. For this purpose, the accuracy of fire spread predictions is estimated by comparison with satellite active fire data for eight large wildfires in Portugal. The quantification uncertainty of was focused on the environmental input variables, leaving out the uncertainty regarding fire spread model parameters, i.e. the empirical values constant throughout the simulations (e.g. adjustment factors). Uncertainties resulting from knowledge limitations and model structure were also not considered. Finally, we discuss how integrating uncertainty can help to improve fire spread predictions and to provide useful information for researchers and fire managers. 


\section{Data and Methods}

\subsection{Case Studies}

Over 3.4 Mha burned in Portugal between 1980 and 2010 (JRC, 2011), corresponding to ca. $38 \%$ of the total area of the country. This period includes very severe fire seasons, such as those of 2003 and 2005, during each of which area burned exceeded 350,000 ha (Oliveira et al., 2012). The summer of 2003 was characterized by an exceptional heatwave in western Iberia (Trigo et al., 2006) and 2005 coincided with one of the most severe droughts recorded in the entire Iberian Peninsula during the last century (Trigo et al., 2013).

We used the Portuguese fire atlas, which contains over 30 years of annual burnt area perimeters (1975-2013) derived from high resolution satellite imagery (Oliveira et al., 2012). Focusing on very large wildfires, we selected eight events that between 2003 and 2005 in the Center and Southern Portugal and burned over 13,000 ha each (Fig 1). According to the Corine Land Cover 2000 (CLC) (Bossard et al., 2000), forests and shrublands prevailed in the burned areas, respectively coniferous forests and shrublands in central Portugal, and broadleaf evergreen woodlands, shrublands and croplands mixed with natural vegetation in the southern region of the country. 


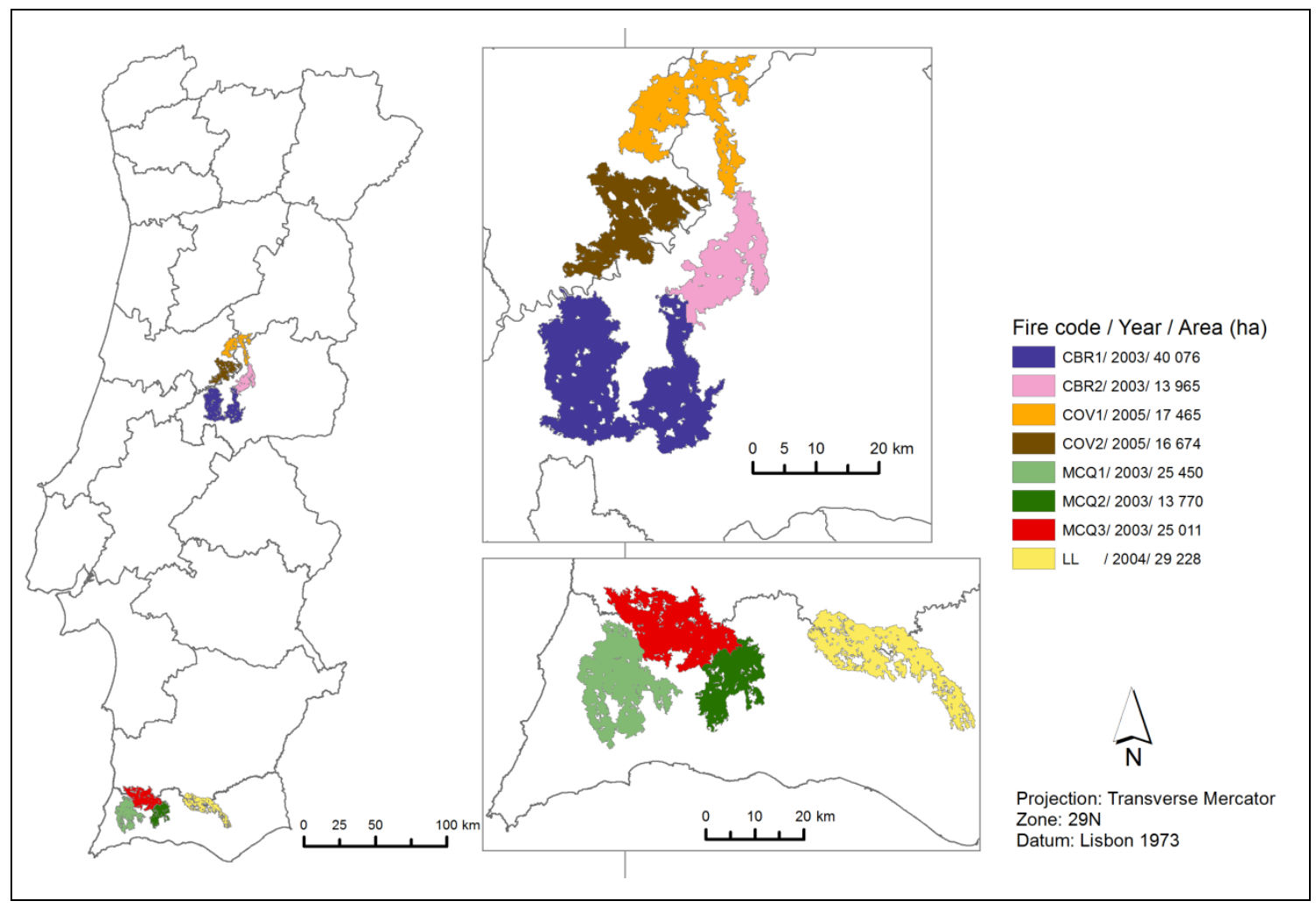

Figure 1. Fire location, year of burning and burnt area extent of the selected case studies.

\subsection{Reference input data}

Spatially explicit fire spread models require data on weather, ignitions and landscape-related variables. Topographic data were acquired from the NASA Shuttle Radar Topography Mission (SRTM) at 90 m spatial resolution (Farr et al., 2007), from which slope and aspect variables were derived.

Fuel maps were created based on expert knowledge by translating CLC land cover classes into fire behavior fuel models as per the Northern Forest Fire Laboratory (NFFL; Anderson, 1982) and the Portuguese custom Fuel Models (PTFM; Fernandes, 2005) typologies (Table 1). Fuel moisture contents (FMC) for dead and live fuels were obtained from Scott and Burgan (2005). Initial dead fuel moisture contents (DFMC) were set to 6\%, 7\% and 8\%, for 1-hr, 10-hr 
and 100-hr time-lag classes respectively. Live fuel moisture contents (LFMC) were set to $60 \%$ and $90 \%$, for herbaceous and woody components, respectively, for all the case studies. Canopy cover density was extracted from the 250m MODIS Vegetation Continuous Fields product (MOD44B) (DiMiceli et al., 2011).

Weather variables, including temperature, precipitation, relative humidity, wind speed and direction, were simulated at $10 \mathrm{~km}$-hourly resolution using the PSU/NCAR mesoscale model (MM5, Grell et al., 1994), driven by ERA40 reanalysis data (Uppala et al., 2005) at the domain boundaries. Simulated weather data were available for the period 1977-2007 with proven capabilities to reproduce the most relevant regional climatic and circulation patterns (e.g. Jerez et al., 2013).

Table 1. Reference CLC land cover class to fuel model assignment, for NFFL and PTFM typologies and correspondent LFMC (\%) ranges.

\begin{tabular}{ll|cc|cc}
\hline & & \multicolumn{2}{|c|}{ NFFL } & \multicolumn{3}{c}{ PTFM } \\
Corine Land Cover (CLC) class & Fuel & Woody & Fuel & Woody \\
& Non-irrigated arable land & 1 & $\mathrm{~b}$ & 224 & $60-120$ \\
& model & LFMC & model & LFMC \\
\hline $221^{\mathrm{a}}$ & Vineyards & 1 & $\mathrm{~b}$ & 224 & $60-120$ \\
222 & Fruit trees and berry plantations & 1 & $\mathrm{~b}$ & 224 & $60-120$ \\
$223^{\mathrm{a}}$ & Olive groves & 1 & $\mathrm{~b}$ & 224 & $60-120$ \\
231 & Pastures & 1 & $\mathrm{~b}$ & 232 & $\mathrm{~b}$ \\
241 & Annual crops associated with permanent crops & 1 & $\mathrm{~b}$ & 224 & $60-120$ \\
242 & Complex cultivation patterns & 1 & $\mathrm{~b}$ & 232 & $\mathrm{~b}$ \\
243 & Land principally occupied by agriculture, with & 5 & $60-100$ & 237 & $60-100$ \\
& Significant areas of natural vegetation & & & & \\
244 & Agro-forestry areas & 1 & $\mathrm{~b}$ & 232 & $\mathrm{~b}$ \\
311 & Broad-leaved forest & 6 & $\mathrm{~b}$ & 221 & $90-150$ \\
312 & Coniferous forest & 6 & $\mathrm{~b}$ & 227 & $60-100$ \\
313 & Mixed forest & 1 & $\mathrm{~b}$ & 227 & $60-100$ \\
$321^{\mathrm{a}}$ & Natural grasslands & 6 & $\mathrm{~b}$ & 232 & $\mathrm{~b}$ \\
322 & Moors and heathland & 6 & $\mathrm{~b}$ & 237 & $60-120$ \\
323 & Sclerophyllous vegetation & 5 & $60-100$ & 234 & $70-120$ \\
324 & Transitional woodland-shrub & 8 & $\mathrm{~b}$ & 235 & $80-140$ \\
333 & Sparsely vegetated areas & 8 & $\mathrm{~b}$ & 235 & $80-140$ \\
334 & Burnt areas & & & \\
\hline
\end{tabular}

${ }^{\mathrm{a}}$ CLC class not represented in the case studies. ${ }^{\mathrm{b}}$ LFMC range not applicable. 


\subsection{Satellite active fire data}

The Moderate Resolution Imaging Spectroradiometer (MODIS) active fire product (MCD14ML) provides information about the location of fires burning at the time of overpass, based on thermal data (Giglio et al., 2003). MODIS active fires are acquired on average four times per day, with a nominal spatial resolution of $1 \mathrm{~km}^{2}$. MODIS can detect fires burning about $1-10 \%$ of the pixel area, however, the detection capabilities depend on fire size, temperature of the fire and surrounding areas, viewing geometry and atmospheric contamination (Giglio, 2010). MODIS has limited capabilities in detecting small fires, especially for large scan angles, due to the low amount of energy that reaches the sensor, but it consistently detects larger fires (Hantson et al., 2013; Hawbaker et al., 2008) and has been used successfully to study their progression (Anderson et al., 2009; Parks, 2014; Veraverbeke et al., 2014).

We used MODIS active fire data for multiple purposes. The start/end dates of each fire event were determined by performing a temporally constrained clustering of all MODIS active fires that overlapped the mapped fire perimeter in the corresponding year of burning (Benali et al., 2016). For each fire, the first active fires detected within the temporal cluster were defined as the ignition points and the centroid coordinates were used to represent location.

Some authors have demonstrated that satellite active fire data can be a reliable and accurate data source to monitor the progression of large wildfires (Parks, 2014; Veraverbeke et al., 2014). Here, we assumed MODIS active fires as the reference fire spread data and estimated the discrepancy between the satellite-derived patterns and the simulated fire growth (Sá et al., under review). The "discrepancy" between both sources of data should be understood as the difference between two measures that ought to be similar, even if both are inaccurate representations of 
reality. We assumed the spatial discrepancy is representative of fire spread simulation accuracy, where lower discrepancy was interpreted as a closer match between the simulated and satelliteobserved fire growth and consequently a higher prediction accuracy.

The spatial discrepancy (hereafter, $\mathrm{SpD}$ ) was defined as the minimum Euclidean distance between a MODIS active fire pixel and the nearest simulated cell burning at the time of satellite overpass. Each MODIS active fire pixel has an associated area and the sub-pixel location of the fire front is unknown. Therefore, we calculated the minimum Euclidean distance between all the possible sub-pixel locations within the MODIS active fire pixel and the closest simulated pixel. Finally, for each case study, we calculated the median of the spatial discrepancies computed for each active fire. Details of this methodology are presented in Sá et al. (under review).

\subsection{Reference fire spread simulations}

To simulate fire spread over the selected case studies, we used the FARSITE fire modeling system (Finney, 2004), due to its recognized capability for providing acceptable fire growth and behavior predictions of historical fires (Cochrane et al., 2012; Papadopoulos and Pavlidou, 2011; Sullivan, 2009), including in Mediterranean areas (e.g. Arca et al., 2007). FARSITE is based on

Rothermel's semi-empirical fire spread model, using separate models for surface fire spread (Rothermel, 1972), crown fire transition (van Wagner, 1977), and crown fire spread (Rothermel, 1991).

Temperature and relative humidity were provided as streams of minimum and maximum daily data, while wind direction and speed were supplied as gridded hourly data streams. Ignitions were defined using satellite active fire data. Topographic variables and fuels were provided as gridded data. 
Given the large number of simulations, we used FARSITE 4 command line version with a landscape cell-size of $100 \mathrm{~m}$ and an hourly time step. We enabled crown fire and no-wind noslope ROS for the spread rate of back fires. The ROS adjustment factors were set to one (i.e. no adjustment). A 3-day conditioning period was used to re-calculate the DFMC prior to the start of the simulations and represent local weather conditions, using Nelson's (2000) model. Spotting and fire suppression were not simulated due to their stochastic nature and unavailability of information, respectively.

The input variables described in section 2.2 , along with the model settings described in this section, were used to perform deterministic simulations for the eight case studies without integrating uncertainty, and are hereafter referred to as reference.

\subsection{Uncertainty assessment}

Depending on the aim and nature of the modeling process, as well as the type of variables used, uncertainty can be quantified using a wide range of methods (e.g. Refsgaard et al., 2007). A key point in uncertainty assessment is the availability of reliable independent data, i.e. alternative data sets representing the target variable(s).

We followed a data-based uncertainty approach for the variables for which reliable independent data sets were available (e.g. relative humidity and temperature). For the remaining variables we performed multi-model simulations, either using the uncertainty information already provided in the data sets (e.g. tree cover), or by comparing them with independent simulations (e.g. wind speed and direction). When no independent data were available, we estimated uncertainty based on used expert knowledge and literature (e.g. DFMC and LFMC).

For each variable, we calculated the frequency of values falling under each uncertainty bin. The frequencies were normalized, representing the probability of a given uncertainty value being 
sampled. Therefore, the histograms were the basis for the sampling procedures used in the propagation of uncertainty throughout the fire spread model (see section 2.6).

\subsubsection{Weather}

We collected minimum and maximum daily temperature and relative humidity data measured at over 100 meteorological stations from the Sistema Nacional de Informação de Recursos Hídricos (SNIRH, 2015) and defined uncertainty as the difference between measured and simulated data. Positive uncertainty values mean that measured values were higher than simulated ones. The meteorological stations were located over the entire Portuguese mainland and the analysis was constrained to the summer periods (July-September) of 2003, 2004 and 2005.

Wind variables are also commonly measured at meteorological stations. However, they are often considered less reliable than other standard meteorological variables, being highly conditioned by the location of the station and often reflecting fine-scale patterns (Azorin-Molina et al., 2014). Alternatively, we defined wind speed and direction uncertainty using a multi-model ensemble approach (Palmer et al., 2005; Refsgaard et al., 2007) based on independent wind simulations from the Weather Research and Forecasting (WRF) model (Skamarock et al., 2005) with 5km-3hour spatial and temporal resolution, respectively (Ferreira et al., 2012), and covering Portugal for the 2000-2005 period. When compared with reference wind simulations, both had different time spans, and different spatial and temporal resolutions. We limited the comparison between both data sets to the summer periods of 2003, 2004 and 2005. The WRF data set was upscaled to a $10 \mathrm{~km}$ spatial resolution by calculating the circular mean of the corresponding pixels within the coarser MM5 pixel, while the MM5 simulations were converted from hourly to 3hour temporal resolution by calculating the circular mean. Uncertainty was estimated by 
calculating the circular distance for wind direction, and for wind speed, the difference between both data sets at a common 10km-3hour resolution.

\subsubsection{Ignitions}

We divided the uncertainty in wildfire ignitions into two distinct and uncorrelated components: location (spatial) and timing (temporal). Both estimates were based on Benali et al. (2016) regarding a database of large wildfires $(>1,000)$ that occurred in Portugal between 2001 and 2009. Uncertainty was estimated by calculating the Euclidean distance and the time lag between the location and date of satellite-derived and field-reported ignitions, respectively. A large number of reported ignitions were located outside the fire perimeters, thus we constrained the comparison to ignitions located within $2 \mathrm{~km}$ of the fire perimeter

\subsubsection{Vegetation}

We focused on the uncertainty associated with fuel models, fuel moisture contents and tree cover. A fire behavior fuel model is a numerical description of the structure and composition of the surface layer (up to $2 \mathrm{~m}$ height) of a burnable vegetation type, comprising all organic matter capable of flaming combustion (Albini, 1976). For large areas, where detailed and reliable fuel maps are not available, often the solution is to use vegetation type maps and assign fuel models, assuming spatial homogeneity (e.g. Arca et al., 2007; Fisher, 1982; Salis et al., 2013). Uncertainty arising from this conversion process has not been quantified, although Salazar (1985) investigated the impact of fuel model variations on fire behavior simulations using the two-fuel-model concept. We analyzed the uncertainty resulting from: i) choice of the fuel model typology and, ii) land cover class to fuel model conversion. ।

To analyze the impact of the uncertainty associated with fuel typology, each land cover class 
was converted to the PTFM fuel scheme and compared with reference simulations (see Table 1). The Instituto da Conservação da Natureza e Florestas (ICNF) recently released a fuel map for Portugal (ICNF, 2014), created by converting a detailed 100 m national land use map for 2007 (COS2007) to the NFFL and PTFM fuel typologies. We calculated the percentage of ICNF 2007 fuel classes corresponding to each CLC 2006 class (EEA, 2007). This percentage reflects the probability of assigning a given NFFL (or PTFM) fuel model to a specific CLC class, hereafter referred to as confusion matrix (Table 2). In order to keep only the most representative fuel models, for each CLC class we removed all ICNF fuel models with frequencies below 2.5\%, keeping at least $95 \%$ of the data (total coverage). Additionally, we performed a similar analysis using the PTFM fuel scheme (see S1 Table 1), to assess the extent to which results depend on fuel typology.

Table 2 - Confusion matrix of CLC to NFFL fuel models assignment.

\begin{tabular}{|c|c|c|c|c|c|c|c|c|c|}
\hline \multirow[b]{2}{*}{$\begin{array}{l}\text { CLC } \\
\text { class }\end{array}$} & \multicolumn{9}{|c|}{ NFFL fuel model } \\
\hline & 1 & 2 & 4 & 5 & 6 & 7 & 8 & 9 & Total coverage $^{a}$ \\
\hline 211 & 59.6 & 31.0 & & 5.5 & & & & & 96.1 \\
\hline $221^{\mathrm{b}}$ & 39.6 & 17.0 & 9.0 & 19.3 & & 12.2 & & 2.6 & 99.7 \\
\hline 222 & 24.1 & 15.4 & 7.8 & 41.2 & & 7.0 & & 4.4 & 99.9 \\
\hline $223^{\mathrm{b}}$ & 28.1 & 28.3 & 7.8 & 25.8 & & 7.7 & & & 97.7 \\
\hline 231 & 47.1 & 25.5 & 3.9 & 18.2 & & 3.0 & & & 97.7 \\
\hline 241 & 50.4 & 13.3 & 4.0 & 17.7 & & 11.0 & & 3.6 & 99.9 \\
\hline 242 & 48.7 & 18.5 & 5.4 & 15.2 & & 9.3 & & 2.9 & 99.9 \\
\hline 243 & 19.3 & 16.9 & 11.5 & 32.5 & & 16.5 & & 3.1 & 99.7 \\
\hline 244 & 11.5 & 69.3 & & 16.8 & & & & & 97.6 \\
\hline 311 & & 25.9 & & 40.4 & & 27.5 & & 2.3 & 96.1 \\
\hline 312 & & & 4.7 & 8.7 & & 78.1 & & 4.8 & 96.3 \\
\hline 313 & & 5.5 & 4.7 & 19.8 & & 61.1 & & 6.3 & 97.4 \\
\hline $321^{\mathrm{b}}$ & 4.2 & 16.7 & 36.0 & 36.8 & & 4.9 & & & 98.6 \\
\hline 322 & 2.9 & 9.3 & 40.0 & 37.1 & & 8.2 & & & 97.4 \\
\hline 323 & & 13.3 & 12.6 & 66.6 & & 3.7 & & & 96.2 \\
\hline 324 & 2.6 & 7.6 & 19.6 & 32.3 & & 34.9 & & & 97.1 \\
\hline 333 & & 11.1 & 32.9 & 46.1 & & 7.0 & & & 97.0 \\
\hline 334 & 5.8 & 12.4 & 20.8 & 35.7 & & 23.6 & & & 98.2 \\
\hline
\end{tabular}

Each data entry of the table corresponds to the frequency that a NFFL fuel model is assigned to a given CLC class.

${ }^{a}$ sum of fuel model frequencies; ${ }^{b}$ not represented in the case studies.

The fuel moisture content (\%) is the weight of water in dead or live fuel particles divided by 
the sample oven dry weight (e.g. Matthews, 2014). Uncertainty in DFMC was defined according to the different moisture scenarios presented by Scott and Burgan (2005), considering ranges of 3-12\%, 4-13\% and 5-14\% for 1-hr, 10-hr and 100-hr time-lag classes, respectively. We defined plausible LFMC ranges for each fuel model based on expert knowledge, both for NFFL and PTFM fuel typologies (Table 1). For example, negative uncertainty corresponded to vegetation drier than the reference. Additionally, we investigated the impact of DFMC uncertainty on simulation accuracy for several conditioning period lengths.

The MODIS tree cover product provides a measure of uncertainty defined as the standard deviation of the 30 models used to generate a given canopy cover density value (DiMiceli et al., 2011). Assuming a normal distribution, characterized by the mean (i.e. the tree cover pixel value) and its standard deviation, we generated multiple tree cover values for each pixel. For example, a positive uncertainty represented tree cover values higher than the mean (i.e. reference).

\subsection{Uncertainty propagation through simulations}

Uncertainties in the input variables were i) independently estimated a priori, ii) propagated through the fire spread modeling system, and iii) their impact was assessed downstream by analyzing simulation outputs (details in next section). When one variable was perturbed, all other variables were kept constant, allowing us to focus on the individual impact of its uncertainty in fire spread simulations.

For maximum and minimum daily temperature and relative humidity, wind direction and speed, as well as tree cover, we sampled 100 values from the uncertainty histogram of each variable (see section 2.5.1). Fire spread simulations were performed independently, i.e. varying one variable at a time, setting a new variable value by adding uncertainty to the reference value.

Regarding the spatial and temporal ignition uncertainties, we sampled 100 values from the 
uncertainty histogram of each variable (see section 2.5.2). For the spatial uncertainty, we generated random ignition points within the fire perimeter (Amatulli et al., 2007), with a distance to the reference location equal to the sampled uncertainty value. For the temporal uncertainty, the sampled value was used to start the simulation before or after the reference ignition time and simulations were run until the end date regardless of the uncertainty signal.

For fuel model assignment uncertainty we converted each land cover class to a NFFL fuel model based on the confusion matrix (see Table 2). The number of times a land cover class was translated to a given fuel model was determined by the frequency in the confusion matrix. Uncertainty was propagated in two distinct ways: i) conversion was performed class by class to separate the impact of assignment uncertainty at land cover class level, and ii) conversion was performed for all land cover classes simultaneously to evaluate the overall impact of fuel model assignment uncertainty. For the latter case, a total of 100 combinations of land cover - fuel model assignments were defined.

Similarly, for the fuel typology uncertainty we investigated the overall impact at the impact at the land cover class level. For the first analysis, we replaced the conversion of each land cover class to a NFFL fuel model by a PTFM fuel model, one class at a time (see section 2.5.3 and Table 1). For the second analysis, for each case study we performed 100 fire spread simulations by converting all land cover classes to the PTFM fuel typology simultaneously, based on the confusion matrix.

All fuel-related uncertainty propagation simulations that predicted a burnt area that overlaid less than $5 \%$ of the area of the targeted fuel model were excluded from the analysis, because the impact of uncertainty could not be assessed. For instance, this occurred when a fuel model was present in the landscape but the simulation never or barely reached it. 
For DFMC and LFMC, we sampled 20 equidistant values within the uncertainty ranges of each fuel model, assuming Uniform distributions. Live fuels are an important component of Mediterranean wildlands, both in shrublands (Anderson et al., 2015) and in the forest understory (Fernandes, 2009). Since only two NFFL fuel models have live components, we also analyzed the impact of LFMC uncertainty using the PTFM fuel typology to understand if responses were affected by the fuel scheme.

\subsection{Uncertainty propagation analysis}

Uncertainty propagation analysis can be done by estimating the impact of input data variability with respect to fixed reference values (Bachmann and Allgöwer, 2002; Refsgaard et al., 2007). We assessed the impact of uncertainty of each variable by analyzing variations in the resulting spatial discrepancy and fire growth ratios. To estimate the relative impact of uncertainty on the satellite-simulation spatial discrepancy, we calculated the spatial discrepancy ratio $\left(\mathrm{SpD}_{\text {ratio }}\right)$ :

$$
S p D_{\text {ratio }_{i, j}}(\%)=\frac{S p D_{i, j}-S p D_{R E F_{j}}}{S p D_{R E F_{j}}} \times 100
$$

where $S p D_{i, j}$ is the spatial discrepancy for the $\mathrm{i}$-th uncertainty propagation simulation for the $\mathrm{j}$-th case study and $S p D_{R E F}$ is the spatial discrepancy for the reference simulation. A positive ratio means that propagating uncertainty through the model leads to a larger satellite-simulated discrepancy, i.e. a lower satellite-simulated agreement and a decrease in the $\mathrm{SpD}_{\text {ratio, }}$, when compared with the reference simulation. Analogously we calculated the fire growth rate ratio $\left(\mathrm{FGR}_{\text {ratio }}\right)$ defined as the simulated burnt area extent divide by the actual duration of the fire spread simulation. 
The $\mathrm{SpD}_{\text {ratio }}$ and $\mathrm{FGR}_{\text {ratio }}$ were calculated for all uncertainty propagation simulations, for all case studies. We analyzed the overall and individual impact of uncertainty in each variable. For the overall analysis, we explored how the model output variability changed with uncertainty of input variables. For the individual analysis, we evaluated the range of responses of model outputs to different values of uncertainty. In general, the distribution of predictive uncertainty does not follow a Normal distribution when models have nonlinear equations (Beven and Binley, 1992). We used the $2.5^{\text {th }}$ and $97.5^{\text {th }}$ percentiles of the $\mathrm{SpD}_{\text {ratio }}$ and $\mathrm{FGR}_{\text {ratio }}$ as the $95 \%$ predictive uncertainty boundaries. Statistical measures were calculated per variable individually and intercompared for an overall assessment. A flow chart of the most relevant methodological steps is shown in Fig 2. 


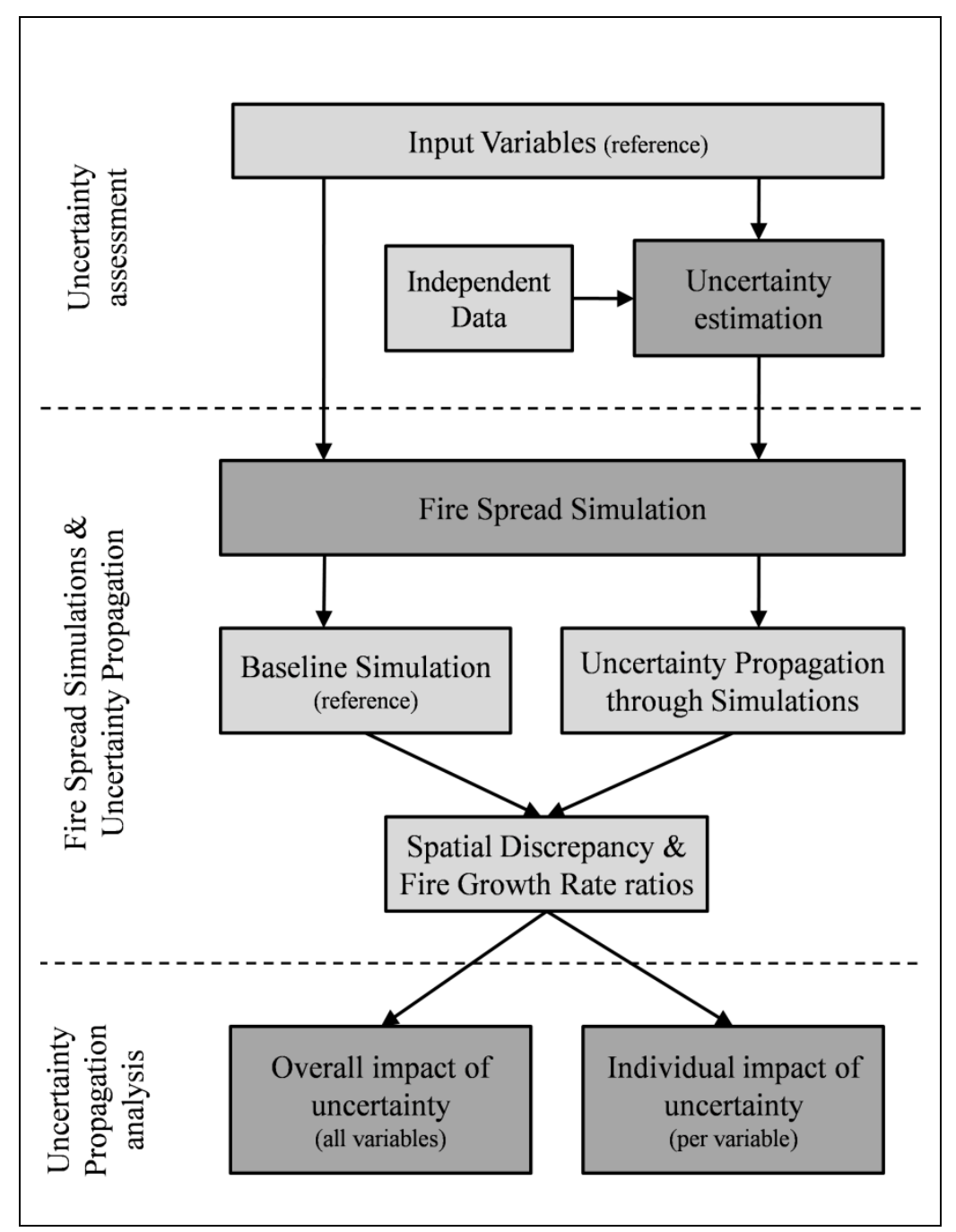

Figure 2. Flowchart of the methodology followed.

Light grey boxes represent inputs and outputs, dark grey boxes represent methodological steps.

\section{Results}

\subsection{Overall impact of uncertainty on fire spread predictions}

The uncertainty associated with wind and fuel-related input variables had the largest impact on the variability of satellite-simulated spatial discrepancy (Fig 3). The uncertainty associated with the land cover - fuel model assignment led to a $95 \% \mathrm{SpD}_{\text {ratio }}$ predictive interval limits ranging from $-100 \%$ to $102 \%$, i.e. ranging from perfect satellite-simulated agreement, to a two- 
fold discrepancy increase. Comparatively, fuel model typology uncertainty had a slightly lower impact on simulation accuracy, with the $\mathrm{SpD}_{\text {ratio }}$ ranging from $-50 \%$ to $25 \%$. Both fuel-related variables were skewed towards negative values.

Wind speed had high impact on simulation accuracy, with the $95 \%$ of predicted $\mathrm{SpD}_{\text {ratio }}$ limits ranging from $-43 \%$ to $99 \%$ (Fig 3). Wind direction was also among the most important variables, with the $\mathrm{SpD}_{\text {ratio }}$ ranging from $-29 \%$ to $97 \%$. Additionally, results showed that the a Normal distribution cannot be fitted to the $\mathrm{SpD}_{\text {ratio }}$ data (see $\mathrm{S} 2$ Table 1 and $\mathrm{S} 2$ Fig 1), supporting the use of percentiles to assess the impact of uncertainty (see section 2.6).

Uncertainty in ignition location and timing had a significant impact on simulation accuracy, with the $\mathrm{SpD}_{\text {ratio }}$ varying between $-59 \%$ and $43 \%$, and between $-42 \%$ and $49 \%$ for spatial and temporal ignition uncertainty, respectively. Uncertainty in the LFMC had a similar impact on the $\mathrm{SpD}_{\text {ratio }}$ for the different fuel typologies, with the $95 \%$ of the $\mathrm{SpD}_{\text {ratio }}$ limits ranging between $66 \%$ and $18 \%$, for the NFFL models.

Uncertainty in relative humidity and tree cover variables had significantly lower impact on prediction accuracy, with the $\mathrm{SpD}_{\text {ratio }} 95 \%$ interval limits varying roughly around $40-50 \%$. Both temperature and $\mathrm{DFMC}$ had low impact on predictive accuracy, with an absolute $\mathrm{SpD}_{\text {ratio }}$ range of ca. $5 \%$. 


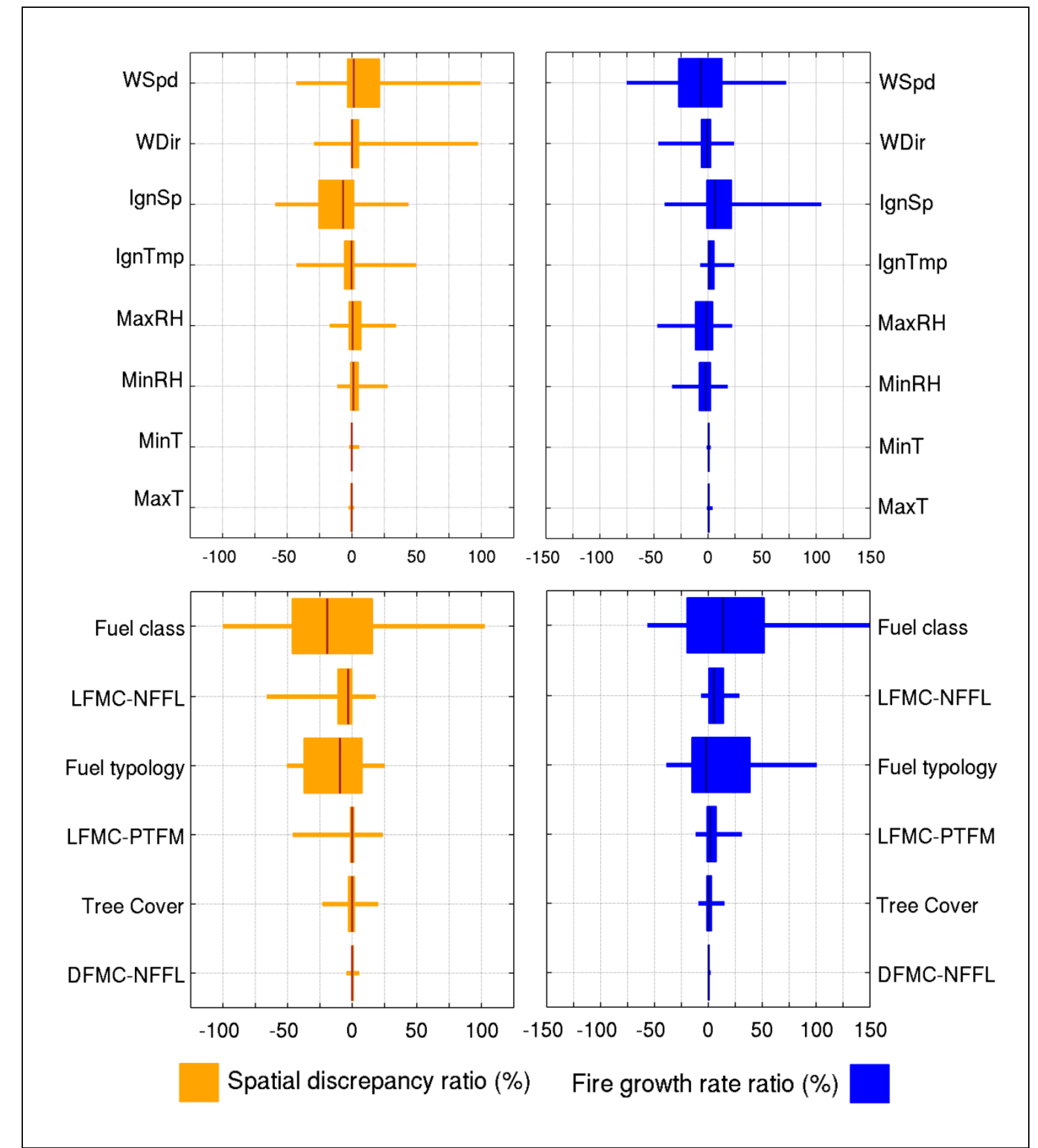

Figure 3. Overall impact of uncertainty in $\mathrm{SpD}_{\text {ratio }}$ (left) and $\mathrm{FGR}_{\text {ratio }}$ (right) variability for the studied variables.

The top panel displays the weather, wind and ignition variables and the bottom one shows the fuel-related variables. The dark orange line represents the median of the $\mathrm{SpD}_{\text {ratio }}$; orange boxes and horizontal lines represent the interquartile range and the $95 \%$ predicted uncertainty limits, respectively; the same description is applicable to the fire growth rate but for blue colors. Variables were abbreviated as follows: WSpd: wind speed; WDir: wind direction; IgnSp: ignition location; IgnTmp: ignition timing; MaxRH: maximum relative humidity; MinRH: minimum relative humidity; MinT: minimum temperature; MaxT: maximum temperature; LFMC: live fuel moisture content; DFMC: dead fuel moisture content. NFFL and PTFM stand for Northern Forest Fire Laboratory and Portuguese custom Fuel Models, respectively. 
In a parallel study, Sá et al. (under review) reported an important fire growth underprediction for the same case studies used here. To compensate such underprediction, the $\mathrm{SpD}_{\text {ratio }}$ followed

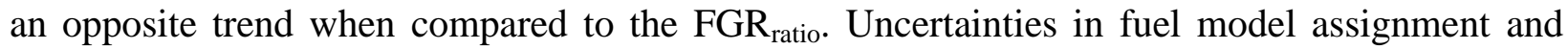
typology, wind speed and ignition location, had very large impacts on the FGR ratio $_{\text {. Some }}$ variables showed $\mathrm{SpD}_{\text {ratio }}$ distributions skewed towards negative values with a wide model response range, for instance fuel model assignment and typology, ignition location and LFMC (Fig 3 and S2 Fig 1). In these cases, propagating the uncertainty through the model led to an improvement in the satellite-simulation agreement. In some cases, such as wind speed and direction, although the variability of the $\mathrm{SpD}_{\text {ratio }}$ was large for both variables, their distribution was not skewed but centered. Implications of the resulting $\mathrm{SpD}_{\text {ratio }}$ are addressed in the Discussion.

\subsection{Impact of individual variable uncertainty on fire spread simulations}

\subsubsection{Weather}

The uncertainty histogram for minimum and maximum daily relative humidity followed a bell-shaped distribution centered on $0 \%$ (Fig 4a,b) with varying asymmetry around the peak and different uncertainty ranges. For both variables, the $\mathrm{SpD}_{\text {ratio }}$ decreased with negative uncertainty (i.e. drier conditions) and increased with positive uncertainty (i.e. wetter conditions), followed by

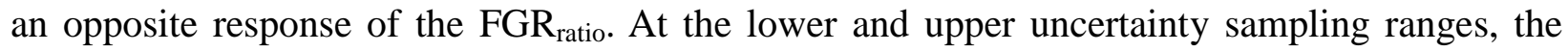
$\mathrm{SpD}_{\text {ratio }}$ decreased and increased about $10-20 \%$ and $20-30 \%$, respectively, for both variables. Variability of the $\mathrm{SpD}_{\text {ratio }}$ was relatively small throughout the uncertainty range, except for extreme positive uncertainty values (40-50\%) driven by steeper responses in three case studies 
(COV2, $L L$ and $M C Q 1$; see S2 Fig 2a,b).

The distribution of the uncertainty histogram for wind direction was centered at $0^{\circ}$, slightly skewed towards positive values (Fig $4 \mathrm{c}$ ). More than $80 \%$ of the sampled uncertainty values were within the $-45^{\circ}$ to $45^{\circ}$ angle range. The response of the $\mathrm{SpD}_{\text {ratio }}$ to wind direction uncertainty was highly variable between case studies, being more abrupt in fires with elongated perimeters (e.g. $C B R 2$ and $L L$; see $\mathrm{S} 2 \mathrm{Fig} 2 \mathrm{c}$ ). For the remaining case studies, the $\mathrm{SpD}_{\text {ratio }}$ increased from $5 \%$ to $40 \%$ at the boundaries of the $95 \%$ limits, almost symmetrically. Increased uncertainty in both directions led to higher $\mathrm{SpD}_{\text {ratio }}$ and lower simulated $\mathrm{FGR}_{\text {ratio, }}$, particularly evident over $45^{\circ}$ of absolute uncertainty. These results reinforce the view that simulated wind direction data were accurate and that uncertainty only had a profound impact on accuracy above an absolute value of $45^{\circ}$. However, the response to wind direction uncertainty varied per case study and both $L L$ and COV2 had maximal $\mathrm{SpD}_{\text {ratio }}$ decreases around $-40^{\circ}$ and $+70^{\circ}$, respectively.

The wind speed uncertainty histogram was centered at $-2 \mathrm{~km} / \mathrm{h}$ and skewed towards negative values, i.e. reference wind speed was slightly higher than the alternative data (Fig $4 d)$. For the 95\% predictive limits, the $\mathrm{SpD}_{\text {ratio }}$ increased by $20 \%$ to $60 \%$ at the lower uncertainty sampling boundary, and decreased by 20 to $35 \%$ at the upper boundary. Positive wind speed uncertainty resulted in higher prediction accuracy due to larger simulated fire growth rates, counterbalancing the general underprediction in the reference simulations. Variability the $\mathrm{SpD}_{\text {ratio }}$ increased with uncertainty in both directions, and was particularly high for negative uncertainty. Variability of the $\mathrm{SpD}_{\text {ratio }}$ and $\mathrm{FGR}_{\text {ratio }}$ exhibited opposite response patterns. Increased uncertainty led to a smaller and higher range of $\mathrm{SpD}_{\text {ratio }}$ and $\mathrm{FGR}_{\text {ratio, }}$, respectively; while decreased uncertainty led to higher and lower range of $\mathrm{SpD}_{\text {ratio }}$ and $\mathrm{FGR}_{\text {ratio, }}$, respectively. The response of the $\mathrm{SpD}_{\text {ratio }}$ to wind speed uncertainty was highly variable for each case study, ranging from highly insensitive, for 
the $M C Q 2$ and $C B R 1$ case studies, to highly sensitive, for the $L L$ and $C O V 2$ case studies (see $\mathrm{S} 2$ Fig 2d). For all case studies, variability was much larger for negative than positive uncertainty.
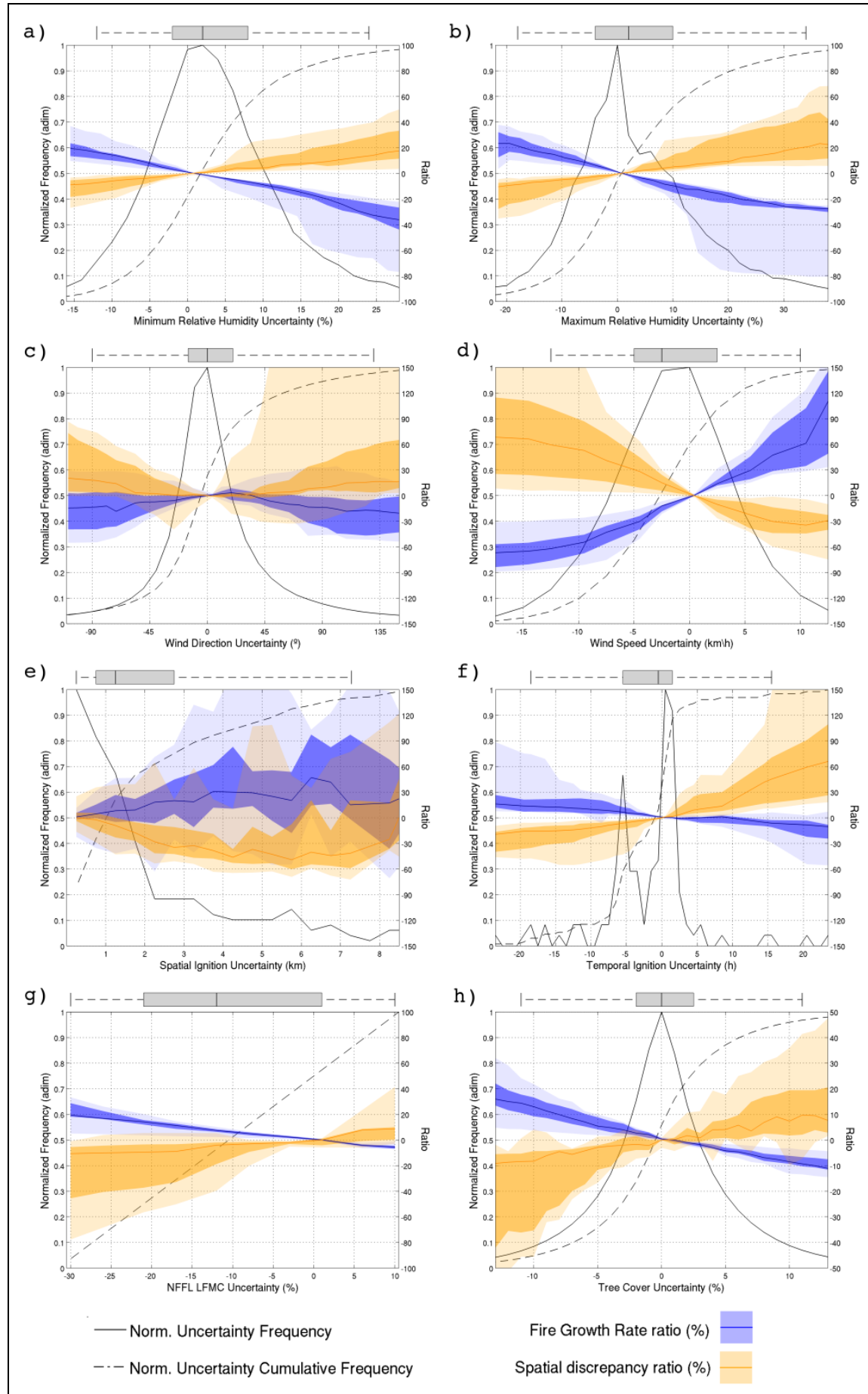

Figure 4. Impact of uncertainty in weather, wind, ignitions, LFMC and tree cover, on the $\mathrm{SpD}_{\text {ratio }}$ and $\mathrm{FGR}_{\text {ratio. }}$

Minimum and maximum daily relative humidity are shown in a) and b); Wind direction and speed in c) 
and d); Ignition location and timing in e) and f); LFMC of NFFL fuel models in g) and tree cover in $\mathrm{h}$ ). The dark orange line represents the median of the $\mathrm{SpD}_{\text {ratio }}$, the orange and light orange areas represent the interquartile range and the $95 \%$ predicted uncertainty limits, respectively; the dark blue line represents the median of the $\mathrm{FGR}_{\text {ratio, }}$, the blue and light blue areas represent the interquartile range and the $95 \%$ predicted uncertainty limits, respectively. The grey box and whiskers delimit the interquartile range and 95\% limits of the sampled uncertainty, respectively.

\subsubsection{Ignitions}

For ignition location, a lower number of uncertainty values was sampled with increased uncertainty, with $80 \%$ of the values sampled below $3500 \mathrm{~m}$ (Fig 4e). In general, the $\mathrm{SpD}_{\text {ratio }}$ decreased with increased spatial ignition uncertainty up to $6000 \mathrm{~m}$, increasing above that value, while the FGR ratio $_{\text {had }}$ opposite response. Given the large variability observed, a distinct trend was not clear (see section 2.6). However, ignition spatial uncertainty had a large impact on simulation accuracy, with the $\mathrm{SpD}_{\text {ratio }}$ ranging from $-60 \%$ to over $80 \%$ in some case studies (Fig 4e and S2 Fig 2e).

Temporal ignition uncertainty had a distinct bimodal histogram, with peaks around $1 \mathrm{~h}$ and 6h (Fig 4f), corresponding to the average time lag between early afternoon and early nighttime MODIS acquisitions. In general, negative temporal ignition uncertainty (i.e. fire starting before reference ignition date) led to higher prediction accuracy, shown by the consistent decrease in the spatial discrepancy ratio. Since fire growth was generally underpredicted, starting simulations earlier led to a larger satellite-simulated agreement. The response to uncertainty was highly asymmetrical: for the $95 \%$ limits, the $\mathrm{SpD}_{\text {ratio }}$ decreased by $5 \%$ to $45 \%$ at the lower uncertainty sampling boundary, but increased by $20 \%$ to more than $150 \%$ at the upper boundary. This asymmetric trend was observed in all case studies, but was particularly pronounced in the $L L$ case study (see S2 Fig 2f), a fast moving wildfire for which the ignition points were late and scattered MODIS detections (Sá et al., under review). 


\subsubsection{Vegetation}

The uncertainty in fuel model assignment showed larger $\mathrm{SpD}_{\text {ratio }}$ variability in the most fireaffected land cover classes, namely for broadleaved and coniferous forests (CLC 311 and 312) and shrublands (CLC 322-324) (Fig 5). Forests have large spatial variability of the understory fuel layer. Interestingly, the two major forest types had opposite responses to uncertainty. Changing the fuel model assigned to coniferous forests (CLC 312) increased the $\mathrm{SpD}_{\text {ratio }}$ from $1 \%$ to around $100 \%$, while for broadleaf forests (CLC 311) decreased the $\mathrm{SpD}_{\text {ratio }}$ by $10 \%$ to $75 \%$. Uncertainty in fuel model assignment for shrubland classes also caused a large impact on simulations, with the $\mathrm{SpD}_{\text {ratio }}$ varying from $-100 \%$ to $85 \%$, skewed towards lower values. The distribution of the fuel models assigned in the current work and by the ICNF showed large discrepancies (S3 Fig 1). The results for the alternative PTFM fuel typology were very similar (S3 Fig 2).

Overall, the impact of the uncertainty arising from fuel model typology was lower than that generated by the fuel model assignment. For broadleaf forests, the $\mathrm{SpD}_{\text {ratio }}$ varied from $-60 \%$ to $10 \%$, showing a relevant accuracy improvement. Conversely, the impact of uncertainty in coniferous forests was very low. Shrubland classes exhibited different patterns. The $\mathrm{SpD}_{\text {ratio }}$ increased by changing fuel typology for sclerophyllous vegetation (CLC 323), ranging from 0\% to $50 \%$, while for transitional woodland-shrub (CLC 324) the $\mathrm{SpD}_{\text {ratio }}$ decreased by the same magnitude.

Similarly to fuel model assignment, the impact of using a different fuel model typology was dependent on the coverage of each land cover class. The impact was generically higher in shrublands (CLC 323, 324) and broadleaf forests (CLC 311). For agricultural classes (CLC 222, $241,242,243$ ) and mixed forest (CLC 313) the impact of uncertainty was low since they were 
under-represented in the case studies. The opposite $\mathrm{FGR}_{\text {ratio }}-\mathrm{SpD}_{\text {ratio }}$ response was also evident for fuel uncertainty, due to the already mentioned overall fire growth underprediction.

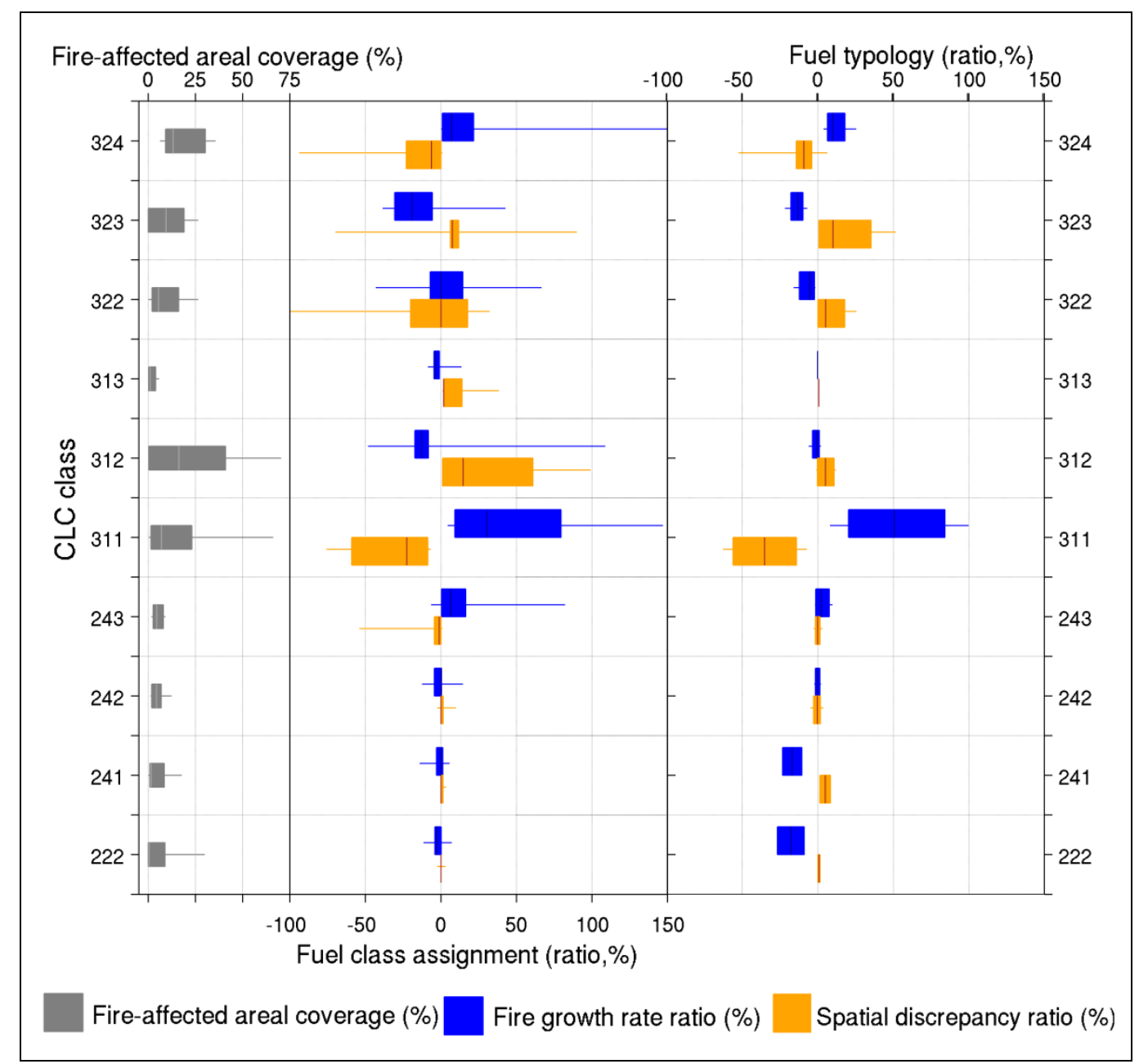

Figure 5. The impact of NFFL fuel model assignment and typology uncertainty on the $\mathrm{SpD}_{\text {ratio }}$ and $\mathrm{FGR}_{\text {ratio, }}$ per land cover class.

Uncertainty in fuel model assignment had a relevant impact on the $\mathrm{SpD}_{\text {ratio }}$ for most case studies, with a maximum range of $-100 \%$ to $180 \%$ for COV2 (Fig 6). In five out of eight case studies, the satellite-simulation discrepancy consistently decreased when integrating uncertainty in fuel model assignment. Consistent with the previous analysis (see Fig 5), case studies with larger coverage of shrublands and broadleaf forests showed higher $\mathrm{SpD}_{\text {ratio variability. When }}$ 
compared with fuel model assignment, the uncertainty in fuel typology had lower impact at the case study level.

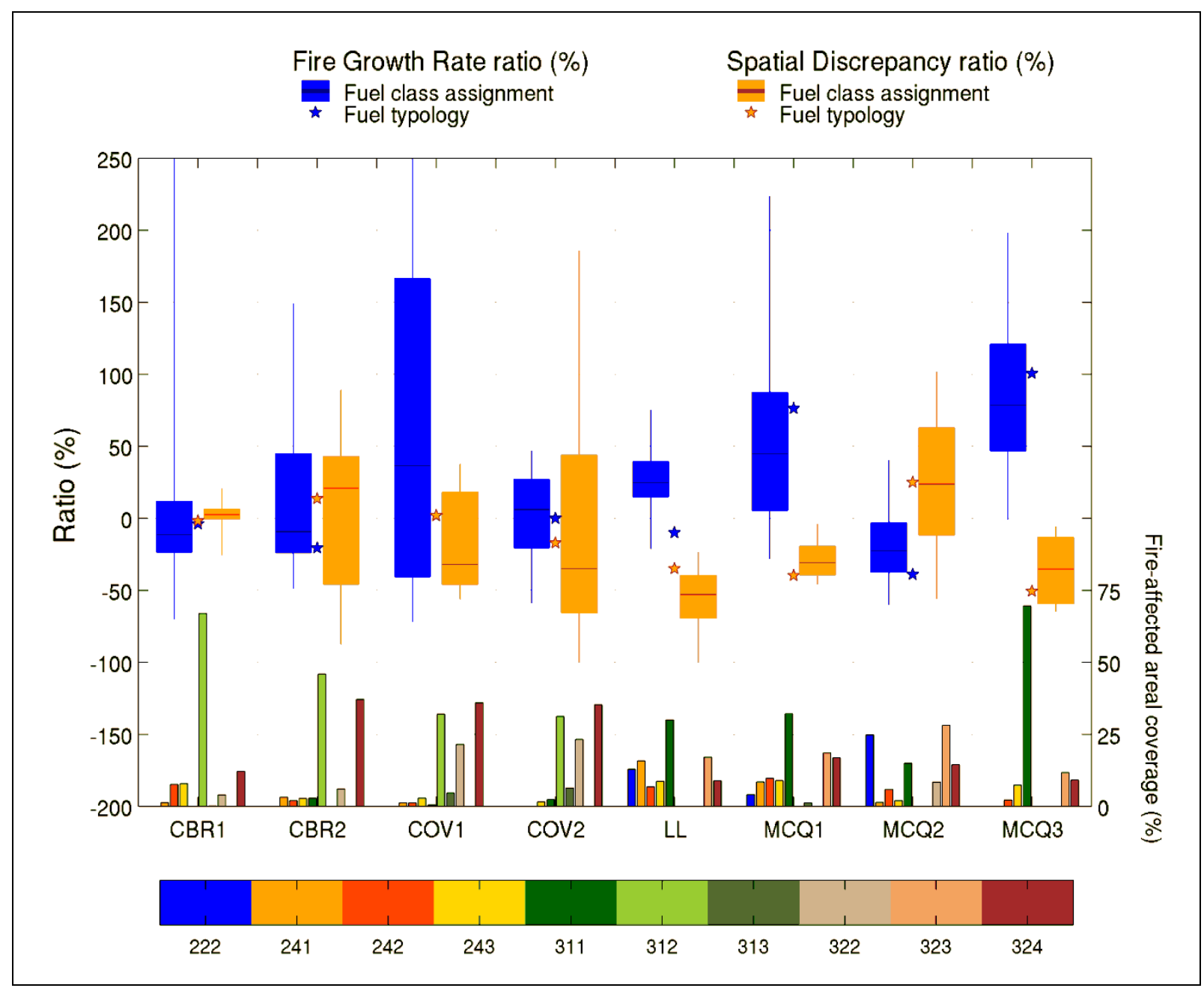

Figure 6. Impact of fuel model assignment and typology uncertainty on the $\mathrm{SpD}_{\text {ratio }}$ and FGR $_{\text {ratio, }}$, per case study.

Negative LFMC uncertainty resulted in higher prediction accuracy due to higher simulated FGR $_{\text {ratio. }}$ The $\mathrm{SpD}_{\text {ratio }}$ increased up to about $10-40 \%$ at the upper boundary, and decreased down to $-80 \%$ at the lower boundary (Fig $4 \mathrm{~g}$ ). Results showed low inter-case study variability (see S2 Fig 2g). The LFMC for PTFM fuel models had lower uncertainty range but similar $\mathrm{SpD}_{\text {ratio }}$ and FGR $_{\text {ratio }}$ responses to uncertainty (see S3 Fig 3). For both measures, variability increased with 
uncertainty. The impact of DFMC uncertainty on the variability of $\mathrm{SpD}_{\text {ratio }}$ was only noticeable when disabling the conditioning period, and ranged from $-15 \%$ to $0 \%$ and $0 \%$ to $30 \%$ in the lower and upper distribution ranges, respectively (S3 Fig 4).

The tree cover uncertainty histogram shows a distribution centered at $0 \%$. For the $95 \%$ uncertainty limits, the $\mathrm{SpD}_{\text {ratio }}$ decreased and increased up to $50 \%$ at lower and upper sampling boundaries, respectively (Fig 4h). Positive tree cover uncertainty resulted in lower prediction accuracy, shown by the consistent increase in the $\mathrm{SpD}_{\text {ratio. }}$ Analyzing the impact per fire showed that tree cover had a very small impact for most case studies, except for the $L L, C O V 2$ and $C B R 2$ case studies (see S2 Fig 2h).

\section{Discussion}

\subsection{Understanding uncertainty}

Uncertainty in input variables had a relevant impact on the accuracy of fire spread predictions, defined here as the discrepancy between satellite and simulated fire growth patterns. The response of $\mathrm{SpD}_{\text {ratio }}$ and $\mathrm{FGR}_{\text {ratio }}$ to uncertainty differed widely among variables and exhibited large response ranges for some of them. Uncertainty in wind and fuel data had the largest impacts on the accuracy of fire spread predictions (see Fig 3), as expected (Bachmann and Allgöwer, 2002; Clark et al., 2008; Salvador et al., 2001).

The assessment of uncertainty in fire spread predictions should be performed at the beginning of the modeling process, rather than at the end as is often the case, providing to the fire model user detailed information regarding the response of fire spread predictions to data errors (Refsgaard et al., 2007). It also assists in the prioritization of efforts to reduce uncertainty and improve fire spread predictions. As an example, uncertainty analysis suggested that to 
improve the fire spread predictions for our specific case studies, it would be more efficient to target efforts towards refining fuel model selection and ignition location accuracy, rather than wind speed and direction (see Fig 3 and S2 Fig 1). This was evidenced by the large variability and skewed distribution towards negative $\mathrm{SpD}_{\text {ratio }}$ values when propagating uncertainty in fuel models and ignition location.

Some authors have studied the impact of uncertainty on fire spread simulations. However, to the best of our knowledge, a comprehensive characterization of the uncertainty associated with the major input variables along with a detailed assessment of their impact on the accuracy of simulated fire spread patterns, has not been performed. A key reason behind this is the lack of appropriate independent large scale fire spread evaluation data (Alexander and Cruz, 2013a). Here, we used satellite active fire data as an indicative accuracy measure. We acknowledge that satellite active fires are an "imperfect" data source with associated limitations (Giglio et al., 2003; Hawbaker et al., 2008). However, it has been shown that it provides accurate independent information on the major spatio-temporal patterns of fire progression for large wildfires and can be very useful for evaluation and assessment purposes (Anderson et al., 2009; Hantson et al., 2013; Parks, 2014; Veraverbeke et al., 2014). These data can contribute to the demand of a concerted effort for long-term systematic monitoring of the spread of large wildfires (Alexander and Cruz, 2013a; Alexander and Cruz, 2013b). A detailed discussion regarding the error sources and limitations of satellite data to monitor fire progression, as well as the limitations of the satellite-simulation discrepancy measures, can be found in Sá et al. (under review) and references therein. Information derived from other sources (e.g. ground, airborne) can be potentially used as an alternative (e.g. http://nirops.fs.fed.us/); however, issues related with data availability, coverage, cost and accuracy can significantly undermine their applicability. 
Correlation and co-variation between input variables can have relevant impacts on uncertainty analysis (Refsgaard et al., 2007), however, full independence rarely is attained (Salvador et al., 2001). Maximum and minimum daily temperature $(\mathrm{r}=0.78)$ and maximum and minimum daily relative humidity $(\mathrm{r}=0.69)$ were the only linearly correlated variables. Studying these interactions was beyond the scope of the current work, but we acknowledge that results concerning these variables should be addressed with caution. Future work will be dedicated to further address this issue.

Uncertainties resulting from knowledge limitations, parametric uncertainty and model inaccuracy, were not addressed, neither were those arising from the spatial resolution of the input data. Beven (2002) highlighted the importance of uncertainty stemming from nonlinear sub-grid processes that were often ignored. However, Clark et al. (2008) showed that spatial resolution had little impact on fire spread predictions. Furthermore, we did not simulate spotting processes which can have a large impact on fire behavior, particularly in large wildfires (Alexander and Cruz, 2013b), neither accounted for fire suppression operations.

Extrapolation to other case studies must be done with caution. The impact of uncertainty will be dependent on the range of input values due to the nonlinear nature of fire spread models (Albini, 1976). Focusing on a small set of large wildfires burning under extreme conditions is certainly a biased sample (Finney et al., 2011b). For example, uncertainty can have significantly different impacts on the accuracy of fire spread simulations under different environmental scenarios (Salvador et al., 2001).

In the following sub-sections we disentangle the impact of uncertainty for the major groups of variables: weather, ignitions, and vegetation.

\subsubsection{Weather}


The assumption of wind homogeneity over a coarse grid cell and the intra-hourly fluctuations of average wind speed are important sources of uncertainty (Anderson et al., 2007; Hilton et al., 2015; Sanjuan et al., 2014) that were not addressed in the current work. Instead, we focused on the knowledge uncertainty resulting from discrepancies in wind predictions caused by uncertainties in the initial conditions and the computational representation of the equations of motion (Palmer et al., 2005). The relevance of uncertainties in wind direction and speed (see Fig 3) is consistent with previous studies (Anderson et al., 2007; Bachmann and Allgöwer, 2002; Clark et al., 2008; Salvador et al., 2001).

For wind speed, the $\mathrm{SpD}_{\text {ratio }}$ variability showed an asymmetric response to uncertainty, with a two-fold spatial discrepancy range and median for negative uncertainty, when compared with positive uncertainty (see Fig 4d). These results can be partially due to the unique characteristics of the case studies, such as canopy cover, vegetation height and the structure of vegetation fuels, which affect midflame wind speed (Finney, 2004). Wind speed uncertainty will have significantly larger impact on fires burning in landscapes with low canopy cover, higher proportion of vertical fuels and lower wind direction variability. Regarding wind direction, Clark et al. (2008) stated that it was not an influential variable, while Hilton et al. (2015) showed that it significantly influenced the expansion of fire flanks. Our results demonstrate a very relevant impact of wind direction uncertainty on the accuracy of fire spread predictions and that, in general, simulated wind direction was accurate, since uncertainty propagation led to lower prediction accuracy (see Fig 4c).

Uncertainty concerning relative humidity had a lower than expected impact on fire spread predictions, when compared with the results presented by Anderson et al. (2007). However, larger impact should be expected for wildfires burning under less extreme conditions (Clark et 
al., 2008). Surprisingly, maximum relative humidity had a larger impact than minimum relative humidity (see Fig 3). Simulated daily maximum relative humidity was higher than expected for summer conditions and exhibited larger variability than minimum relative humidity (S4 Fig 1). Our case studies lasted for several days, so it is likely that nighttime conditions played an important role, that, along with the wider range of the uncertainty histogram (Fig 4a,b), may explain the higher impact of maximum than minimum relative humidity uncertainty in prediction accuracy.

\subsubsection{Ignitions}

There are multiple sources of uncertainty regarding wildfire ignitions reported in fire databases (Amatulli et al., 2007; Pereira et al., 2011). As an alternative, we used MODIS active fire data to determine the location and timing of ignitions, which in turn also have multiple sources of uncertainty (Bar-Massada et al., 2012; Giglio et al., 2003; Hawbaker et al., 2008). Nevertheless, satellite-derived ignitions are a valuable data source that can be used alone or as a complement of reported data (Benali et al., 2016).

Uncertainty in ignition location led to significantly higher variability of the $\mathrm{SpD}_{\text {ratio }}$ and

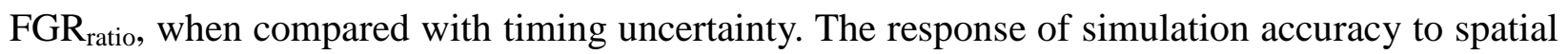
uncertainty was highly variable and showed the least distinctive patterns of all variables studied (Fig 4e). Ignition uncertainty affects predictions due to the complex interactions with weather conditions, fuels and topography (Parisien et al., 2010). It also strongly influences simulated fire patterns (Bar Massada et al., 2011, and references therein), which is consistent with the results shown here, and significantly different from the results of Clark et al. (2008).

A distinct $\mathrm{SpD}_{\text {ratio }}$ response to uncertainty was not clear probably due to the random sampling approach used to define potential ignition locations. However, the choice of constraining 'new' 
ignition locations within the final fire perimeter was an optimistic approach, considering the errors in the Portuguese fire database (Benali et al., 2016; Pereira et al., 2011). It is expected that, in the absence of final fire perimeters (e.g. under operational conditions) and under milder weather conditions, the impact of ignition uncertainty on the accuracy of fire spread predictions will be even larger (Bar Massada et al., 2011). Consequently, impacts should vary greatly from region to region, consistent with the observed large inter-case study response variability.

\subsubsection{Vegetation}

Uncertainty in fuel model assignment and parameterization had large impacts on the accuracy of fire spread predictions. Several authors have stated that small changes in fuel structure can lead to large changes in simulated or observed fire spread (Anderson, 1982; Fernandes et al., 2004; Salazar, 1985). Mapping fuels is a labor-intensive and expensive task, due to their high temporal and spatial variability, large heterogeneity across multiple scales, limitations of remote sensing techniques to map surface fuels, difficulty of establishing a robust mapping protocol and classification subjectivity (Keane and Reeves, 2012). Moreover, uncertainties in moisture content arise from variations in vegetation structure and type, fuel bed depth, canopy cover, soil moisture, topography and weather (see Matthews, 2014 for in-depth discussion). Finally, the assumption of fuel homogeneity in a coarse $100 \mathrm{~m}$ grid cells (Hilton et al., 2015) and scale effects (Salvador et al., 2001) introduce important uncertainties that were not accounted for in this study.

Fuel model assignment uncertainty had a large impact in forest classes, with opposite response patterns (see Fig 5). In Portugal, pine trees dominate the composition of coniferous forests. We assigned NFFL model 6 to coniferous forests, while the ICNF assigned mostly (over 78\% of the times) NFFL model 7 (see Table 1 and Table 2) and never assigned NFFL model 6. 
The main broadleaf forest types in Portugal are deciduous oaks, the evergreens cork oak and holm oak, and blue gum eucalypt, generating large spatial variability in understory composition and structure, which may explain the high impact of uncertainty. We assigned NFFL model 9 to broadleaf forest (CLC class 311), while the ICNF assigned models 2, 5 and 7. For shrubland areas, we assigned model 6 to CLC classes 322-323 and model 5 to CLC class 324, while the ICNF assigned models 4, 5 and 7 (see Table 2 and S3 Fig 1). The fuel models assigned to each case study showed remarkable discrepancies, highlighting the differences resulting from inherent subjectivity in model assignment, but also from significant differences in the spatial detail level of the base vegetation maps.

Results showed that changing the parameterization of fuels models in forests and shrublands had an important impact on the accuracy of fire spread predictions, and led to a decrease in satellite-simulation discrepancies for most case studies (see Fig 5). These results showed the importance of integrating expert knowledge when mapping and parameterizing local fuel models (Keane and Reeves, 2012; Reeves et al., 2009). Results also showed the benefits of using custom fuel models in the reduction of uncertainty and satellite-simulation discrepancy (Salazar, 1985). Comparatively, fuel model uncertainty had a larger relative impact (e.g. when compared with wind speed) on fire spread simulations than shown by Clark et al. (2008), probably in part due to the over simplistic uniform uncertainty distribution they assumed.

The same authors showed that DFMC accounted for more model output variation than fuel model uncertainty, while our results showed a marginal impact of DFMC on fire spread simulations, regardless of the conditioning period length. DFMC ranges were representative of summer conditions in Portugal (Lopes et al., 2006). The FMC are calculated by FARSITE throughout the simulation from environmental conditions and the influence of initial FMC 
vanishes rapidly (Finney, 2004), thus fire spread is barely dependent on the initial DFMC values.

The importance of LFMC on wildfires is complex and subject to debate (Yebra et al., 2013).

Our results showed that LFMC uncertainty has a moderate impact on the accuracy of fire spread predictions, regardless of fuel typology (see Fig 4g). Furthermore, we studied large wildfires that occurred under extreme conditions, and the response of the $\mathrm{SpD}_{\text {ratio }}$ to LFMC uncertainty suggests that LFMC was likely overestimated in the reference simulations. FMC will likely have a larger influence on fires occurring in less extreme conditions (Clark et al., 2008).

Tree cover affects the calculation of fuel moisture and surface wind speed (Finney, 2004), as a consequence, negative uncertainty will render drier fuels, due to decreased shading, and higher midflame wind speed. Although uncertainty in tree cover had relatively low impact on the accuracy of fire spread simulations, it must be noted that the uncertainty ranges were small and estimated by the MODIS algorithm (Figure 4h; DiMiceli et al., 2011). Consequently, higher impacts on the accuracy of fire spread predictions might be expected, particularly under significant year-to-year land cover changes. A comprehensive validation of the MODIS tree cover product is needed for further assessments.

\subsection{Integrating Uncertainty}

Integrating uncertainty to produce reliable fire spread predictions is still relatively new and difficult because fire behavior is highly variable (Finney, 2005). Traditional deterministic predictions based on the best available data fail to provide information regarding the uncertainty that pervades model predictions. Alternatively, probabilistic approaches allow the quantification of predictive uncertainty, identification of prediction limits, and improved understanding of the probability of occurrence of possible fire behavior outcomes (Finney et al., 2011b; Gill, 2001).

Fire managers are used to handle multiple sources of uncertainty when managing wildfires. 
Integrating uncertainty into fire spread predictions will certainly improve risk assessment and the decision-making processes (Anderson et al., 2007; Thompson and Calkin, 2011), especially in an operational context where uncertainty is high and will likely result in large errors (Cruz and Alexander, 2013). However, realistically accounting for uncertainty can only be accomplished if users demand it and acknowledge that even if explanatory power is not improved, useful complementary information can be provided, such as error bounds and probabilistic outcomes (Cruz, 2010).

Previous studies have focused on integrating the uncertainty in meteorological variables to produce probabilistic fire spread predictions (Anderson et al., 2007; Cruz, 2010; Finney et al., 2011a). Our results show that other sources of uncertainty also need to be accounted for, such as ignition location and fuels, as they are important sources of prediction errors.

Our results show that considering normally distributed uncertainty around a mean value of zero can be a considerable over-simplification for meteorological variables (Anderson et al., 2007; Bachmann and Allgöwer, 2002; Cruz, 2010). We recognize the need for better understanding the uncertainties present in meteorological variables, such as wind-terrain interaction, the downscaling of meteorological information from coarse grid cells, the temporal variability of wind speed, and the necessity of integrating them into future ensemble predictions. Additionally, we stress the need for weather forecasts to provide explicit representations of model uncertainty.

Uncertainty in wildfire ignitions is large, especially regarding its location, and should be taken into account in future studies. For satellite-derived ignitions, the use of additional sensors ought to increase the number of clear-sky overpasses and the spatial resolution of active fires (e.g. Schroeder et al., 2014), thus increasing the probability of accurately detecting the location 
and timing of ignitions in any part of the globe. It is crucial that uncertainty in ignition location and timing are integrated (e.g. Amatulli et al., 2007).

Our results for vegetation-related variables show the importance of integrating their uncertainty in future fire spread predictions. When detailed comprehensive information is available for fuel mapping purposes (e.g. LANDFIRE, see Reeves et al., 2009) and while a new paradigm for fuel mapping is not established, we argue that the most efficient procedure would be to explicitly define the uncertainties in fuel model assignment and parameterizations and integrate them in fire behavior simulations. For instance, Reeves et al. (2009) described how expert knowledge was used to classify fuel models based on a majority vote. This is a good example where uncertainty could be integrated by using the multiple fuel classifications done by experts. Alternatively, when fuels are mapped by converting a generic vegetation map, uncertainties in fuel model classifications could be integrated by using the knowledge from multiple fire experts under the assumption that it is likely the best information available (Thompson and Calkin, 2011).

We focused our analysis on the impact of uncertainty that each individual input variable has on the accuracy of fire spread simulations. In reality, several variables will be correlated to some extent (e.g. weather variables; Salvador et al. (2001)) and therefore, their uncertainties will not be completely independent. Future work should focus on the study of such interactions, improving our knowledge on how to integrate the data uncertainty, for instance, in the simulation of 'real' wildfires in an operational context. Under such context, it is expectable that for some variables the uncertainties will decrease (e.g. ignition location) while for others it will increase (e.g. weather forecasts) when compared with the research context presented here.

\section{Conclusions}


The impact of uncertainty in the most relevant variables on fire spread prediction accuracy has not been quantified before. We have shown how uncertainties in input variables of a fire spread modeling framework can influence the quality of the downstream predictions. Results showed that uncertainties in wind speed and direction, fuel model assignment and typology, location and timing of ignitions had important impacts on prediction accuracy.

Uncertainty assessment should be performed at the beginning of the fire modeling process, to enable for: i) the characterization of the most important uncertainties; ii) the identification of target variables where predictions will be likely improved by reducing uncertainty, and iii) an improved characterization of errors associated with fire spread predictions.

Since uncertainties will always be present and our knowledge on fire behavior will continue to be imperfect, understanding and quantifying the impact of uncertainties in model accuracy is essential to help fire managers make better management decisions and, ultimately, to extend our current knowledge. By integrating uncertainty in fire spread predictions one can expect to improve the anticipation of fire behavior estimates and minimize both their negative environment impacts and risk to human life and health.

\section{Acknowledgements}

This study was supported by the FIRE-MODSAT project (EXPL/AGR-FOR/0488/2013) funded by the Fundação para a Ciência e Tecnologia (FCT). We thank: i) the Portuguese forestry service for providing data from the $5^{\text {th }}$ National Forestry Inventory (2005-2006); ii) the MODIS Science team for the satellite products; iii) John Benoit from the USDA Forest Service for assistance with the FARSITE command line version; and iv) Sonia Jerez (University of Murcia) and Juan Ferreira (CESAM-Universidade de Aveiro) for providing the simulated weather data sets. The $\begin{array}{llll}\text { uncertainty } & \text { are } & \text { freely available }\end{array}$ 
https://www.researchgate.net/publication/276290401_Fire_Spread_Uncertainty_Database_\%28v

$1 \% 29$.

\section{References}

Albini, F.A., 1976. Estimating wildfire behavior and effects. USDA For. Serv., Intermt. For. Range Exp. Stn., Ogden, UT. Gen. Tech. Rep. INT-30. 92 p.

Alexander, M.E., Cruz, M.G., 2013a. Are the applications of wildland fire behaviour models getting ahead of their evaluation again? Environmental Modelling \& Software 41, 65-71.

Alexander, M.E., Cruz, M.G., 2013b. Limitations on the accuracy of model predictions of wildland fire behaviour: A state-of-the-knowledge overview. The Forestry Chronicle 89, 372383.

Amatulli, G., Peréz-Cabello, F., de la Riva, J., 2007. Mapping lightning/human-caused wildfires occurrence under ignition point location uncertainty. Ecological Modelling 200, 321-333.

Anderson, H.E., 1982. Aids to determining fuel models for estimating fire behavior. The Bark Beetles, Fuels, and Fire Bibliography, 143.

Anderson, K., Reuter, G., Flannigan, M.D., 2007. Fire-growth modelling using meteorological data with random and systematic perturbations. International Journal of Wildland Fire 16, 174.

Anderson, K.R., Englefield, P., Little, J.M., Reuter, G., 2009. An approach to operational forest fire growth predictions for Canada. International Journal of Wildland Fire 18, 893.

Anderson, W.R., Cruz, M.G., Fernandes, P.M., McCaw, L., Vega, J.A., Bradstock, R.A., Fogarty, L., Gould, J., McCarthy, G., Marsden-Smedley, J.B., 2015. A generic, empirical-based model for predicting rate of fire spread in shrublands. International Journal of Wildland Fire 24, 443-460.

Arca, B., Duce, P., Laconi, M., Pellizzaro, G., Salis, M., Spano, D., 2007. Evaluation of FARSITE simulator in Mediterranean maquis. International Journal of Wildland Fire 16, 563.

Azorin-Molina, C., Vicente-Serrano, S.M., McVicar, T.R., Jerez, S., Sanchez-Lorenzo, A., López-Moreno, J.-I., Revuelto, J., Trigo, R.M., Lopez-Bustins, J.A., Espírito-Santo, F., 2014. Homogenization and Assessment of Observed Near-Surface Wind Speed Trends over Spain and Portugal, 1961-2011*. Journal of Climate 27, 3692-3712.

Bachmann, A., Allgöwer, B., 2002. Uncertainty propagation in wildland fire behaviour modelling. International Journal of Geographical Information Science 16, 115-127.

Bar-Massada, A., Hawbaker, T.J., Stewart, S.I., Radeloff, V.C., 2012. Combining Satellite-Based Fire Observations and Ground-Based Lightning Detections to Identify Lightning Fires Across the Conterminous USA. IEEE Journal of Selected Topics in Applied Earth Observations and Remote Sensing 5, 1438-1447.

Bar Massada, A., Syphard, A.D., Hawbaker, T.J., Stewart, S.I., Radeloff, V.C., 2011. Effects of ignition location models on the burn patterns of simulated wildfires. Environmental Modelling \& Software 26, 583-592. 
Benali, A., Russo, A., Sá, A.C., Pinto, R., Price, O., Koutsias, N., Pereira, J., 2016. Determining Fire Dates and Locating Ignition Points With Satellite Data. Remote Sensing 8, 326.

Beven, K., 2002. Towards a coherent philosophy for modelling the environment. Proceedings of the Royal Society A: Mathematical, Physical and Engineering Sciences 458, 2465-2484.

Beven, K., Binley, A., 1992. The future of distributed models: model calibration and uncertainty prediction. Hydrological processes 6, 279-298.

Bossard, M., Feranec, J., Otahel, J., 2000. CORINE land cover technical guide: Addendum 2000. European Environment Agency Copenhagen.

JRC, 2011. Forest Fires in Europe 2010. JRC Scientific and Technical Reports, p. 98.

Clark, R.E., Hope, A.S., Tarantola, S., Gatelli, D., Dennison, P.E., Moritz, M.A., 2008. Sensitivity Analysis of a Fire Spread model in a Chaparral landscape. Fire Ecology 4.

Cochrane, M., Moran, C., Wimberly, M., Baer, A., Finney, M., Beckendorf, K., Eidenshink, J., Zhu, Z., 2012. Estimation of wildfire size and risk changes due to fuels treatments. International Journal of Wildland Fire 21, 357-367.

Cruz, M.G., 2010. Monte Carlo-based ensemble method for prediction of grassland fire spread. International Journal of Wildland Fire 19, 521.

Cruz, M.G., Alexander, M.E., 2013. Uncertainty associated with model predictions of surface and crown fire rates of spread. Environmental Modelling \& Software 47, 16-28.

Cruz, M.G., Sullivan, A.L., Gould, J.S., Sims, N.C., Bannister, A.J., Hollis, J.J., Hurley, R.J., 2012. Anatomy of a catastrophic wildfire: The Black Saturday Kilmore East fire in Victoria, Australia. Forest Ecology and Management 284, 269-285.

DiMiceli, C., Carroll, M., Sohlberg, R., Huang, C., Hansen, M., Townshend, J., 2011. Annual Global Automated MODIS Vegetation Continuous Fields (MOD44B) at $250 \mathrm{~m}$ Spatial Resolution for Data Years Beginning Day 65, 2000-2010, Collection 5 Percent Tree Cover. University of Maryland, College Park.

Farr, T.G., Rosen, P.A., Caro, E., Crippen, R., Duren, R., Hensley, S., Kobrick, M., Paller, M., Rodriguez, E., Roth, L., 2007. The shuttle radar topography mission. Reviews of geophysics 45.

Fernandes, P., 2005. Equivalência genérica entre os modelos de combustível do USDA Forest Service (Anderson, 1982) e as formações florestais portuguesas. In: Guia metodológico para elaboração do Plano Municipal/Intermunicipal de Defesa da Floresta Contra Incêndios Direção Geral dos Recursos Florestais.

Fernandes, P., Loureiro, C.A., Botelho, H.S., 2004. Fire behaviour and severity in a maritime pine stand under differing fuel conditions. Annals of Forest Science 61, 537-544.

Fernandes, P., 2009. Combining forest structure data and fuel modelling to classify fire hazard in Portugal. Annals of Forest Science 66, 1-9.

Fernandes, P.M., Loureiro, C., Guiomar, N., Pezzatti, G.B., Manso, F.T., Lopes, L., 2014. The 
dynamics and drivers of fuel and fire in the Portuguese public forest. Journal of Environmental Management 146, 373-382.

Ferreira, J., Rocha, A., Castanheira, J.M., Carvalho, A.C., 2012. Dynamical downscaling intercomparison for high resolution climate reconstruction. EGU General Assembly Vienna, Austria. 22 - 27 April 2012.

Finney, M.A., 2004. FARSITE: Fire Area Simulator-Model Development and Evaluation. USDA Research Paper RMRS-RP-4.

Finney, M.A., 2005. The challenge of quantitative risk analysis for wildland fire. Forest Ecology and Management 211, 97-108.

Finney, M.A., Grenfell, I.C., McHugh, C.W., Seli, R.C., Trethewey, D., Stratton, R.D., Brittain, S., 2011a. A Method for Ensemble Wildland Fire Simulation. Environmental Modeling \& Assessment 16, 153-167.

Finney, M.A., McHugh, C.W., Grenfell, I.C., Riley, K.L., Short, K.C., 2011b. A simulation of probabilistic wildfire risk components for the continental United States. Stochastic Environmental Research and Risk Assessment 25, 973-1000.

Fisher, W.C., 1982. Photo guide for appraising downed woody fuels in Montana forests: Grand Fir-Lach-Douglas-Fir, Western Hemlock, Western Hemlock-Western Redcedar, and Western Redcedar cover types. General Technical Report INT-96, Intermountain Forest and Range Experiment Station., 133.

Giglio, L., 2010. MODIS Collection 5 Active Fire Product User's Guide Version 2.4.

Giglio, L., Descloitres, J., Justice, C.O., Kaufman, Y.J., 2003. An Enhanced Contextual Fire Detection Algorithm for MODIS. Remote Sensing of Environment 87, 273-282.

Gill, A., 2001. A transdisciplinary view of fire occurrence and behaviour, Bushfire, pp. 1-12.

Grell, G.A., Dudhia, J., Stauffer, D.R., 1994. A description of the fifth-generation Penn State/NCAR mesoscale model (MM5). NCAR Technical Note NCAR/TN-398+STR, doi:10.5065/D60Z716B.

Hantson, S., Padilla, M., Corti, D., Chuvieco, E., 2013. Strengths and weaknesses of MODIS hotspots to characterize global fire occurrence. Remote Sensing of Environment 131, 152-159.

Hawbaker, T.J., Radeloff, V.C., Syphard, A.D., Zhu, Z., Stewart, S.I., 2008. Detection rates of the MODIS active fire product in the United States. Remote Sensing of Environment 112, 26562664.

Hilton, J.E., Miller, C., Sullivan, A.L., Rucinski, C., 2015. Effects of spatial and temporal variation in environmental conditions on simulation of wildfire spread. Environmental Modelling \& Software 67, 118-127.

Jerez, S., Trigo, R., Vicente-Serrano, S.M., Pozo-Vázquez, D., Lorente-Plazas, R., LorenzoLacruz, J., Santos-Alamillos, F., Montávez, J., 2013. The impact of the North Atlantic Oscillation on renewable energy resources in southwestern Europe. Journal of Applied Meteorology and Climatology 52, 2204-2225. 
Keane, R.E., Reeves, M., 2012. Use of Expert Knowledge to Develop Fuel Maps for Wildland Fire Management, in: A.H. Perera, C.A.D., and C.J. Johnson (ed.), Expert knowledge and its application in landscape ecology. Springer Science and Business Media, LLC, New York, USA, p. $211-228$.

Kochanski, A.K., Jenkins, M.A., Mandel, J., Beezley, J.D., Krueger, S.K., 2013. Real time simulation of 2007 Santa Ana fires. Forest Ecology and Management 294, 136-149.

Liu, Y., Jimenez, E., Hussaini, M.Y., Okten, G., Goodrick, S., 2015. Parametric uncertainty quantification in the Rothermel model with randomised quasi-Monte Carlo methods. International Journal of Wildland Fire 24, 307.

Lopes, S.M.G., Viegas, D.X., Viegas, M.T., de Lemos, L.T., 2006. Moisture content of fine forest fuels in the Central Portugal (Lousa) for the period 1996-2004. Forest Ecology and Management 234, S71.

Matthews, S., 2014. Dead fuel moisture research: 1991-2012. International Journal of Wildland Fire 23, 78-92.

Oliveira, S.L.J., Pereira, J.M.C., Carreiras, J.M.B., 2012. Fire frequency analysis in Portugal (1975 - 2005), using Landsat-based burnt area maps. International Journal of Wildland Fire 21, 48.

Palmer, T.N., Shutts, G.J., Hagedorn, R., Doblas-Reyes, F.J., Jung, T., Leutbecher, M., 2005. Representing Model Uncertainty in Weather and Climate Prediction. Annual Review of Earth and Planetary Sciences 33, 163-193.

Papadopoulos, G.D., Pavlidou, F.-N., 2011. A Comparative Review on Wildfire Simulators. IEEE Systems Journal 5, 233-243.

Parisien, M.-A., Miller, C., Ager, A.A., Finney, M.A., 2010. Use of artificial landscapes to isolate controls on burn probability. Landscape Ecology 25, 79-93.

Parks, S.A., 2014. Mapping day-of-burning with coarse-resolution satellite fire-detection data. International Journal of Wildland Fire 23, 215.

Pereira, M.G., Malamud, B.D., Trigo, R.M., Alves, P.I., 2011. The history and characteristics of the 1980-2005 Portuguese rural fire database. Natural Hazards and Earth System Science 11, 3343-3358.

Reeves, M.C., Ryan, K.C., Rollins, M.G., Thompson, T.G., 2009. Spatial fuel data products of the LANDFIRE Project. International Journal of Wildland Fire 18, 250.

Refsgaard, J.C., van der Sluijs, J.P., Højberg, A.L., Vanrolleghem, P.A., 2007. Uncertainty in the environmental modelling process - A framework and guidance. Environmental Modelling \& Software 22, 1543-1556.

Rothermel, R.C., 1972. A mathematical model for predicting fire spread in wildland fuels. USDA For. Serv. Res. Pap. INT-115.

Rothermel, R.C., 1991. Predicting behavior and size of crown fires in the northern Rocky Mountains. USDA For. Serv. Res. Pap. INT-438.

Sá, A.C.L., Benali, A., Fernandes, P.M., Pinto, R.M.S., Trigo, R.M., Salis, M., Russo, A., Jerez, 
S., Soares, P.M., Schroeder, W., Pereira, J.M.C., under review. Evaluating fire growth simulations using satellite active fire data. Submitted to Remote Sensing of Environment.

Salazar, L.A., 1985. Sensitivity of fire behavior simulations to fuel model variations. Res. Paper PSW-178. Berkeley, CA: Pacific Southwest Forest and Range Experiment Station, Forest Service, U.S. Department of Agriculture, 11.

Salis, M., Ager, A.A., Arca, B., Finney, M.A., Bacciu, V., Duce, P., Spano, D., 2013. Assessing exposure of human and ecological values to wildfire in Sardinia, Italy. International Journal of Wildland Fire 22, 549.

Salvador, R., Pinol, J., Tarantola, S., Pla, E., 2001. Global sensitivity analysis and scale effects of a fire propagation model used over Mediterranean shrublands. Ecological Modelling 136, 175189.

Sanjuan, G., Brun, C., Margalef, T., Cortés, A., 2014. Wind Field Uncertainty in Forest Fire Propagation Prediction. Procedia Computer Science 29, 1535-1545.

Schroeder, W., Oliva, P., Giglio, L., Csiszar, I.A., 2014. The New VIIRS 375m active fire detection data product: Algorithm description and initial assessment. Remote Sensing of Environment 143, 85-96.

Scott, J.H., Burgan, R.E., 2005. Standard fire behavior fuel models: a comprehensive set for use with Rothermel's surface fire spread model. The Bark Beetles, Fuels, and Fire Bibliography, 66.

Skamarock, W., Klemp, J., Dudhia, J., Gill, D., Barker, D., 2005. A description of the Advanced Research WRF Version 2. NCAR Technical Note NCAR/TN-468+STR. 113 p.

Sullivan, A.L., 2009. Wildland surface fire spread modelling, 1990-2007. 3: Simulation and mathematical analogue models. International Journal of Wildland Fire 18, 387-403.

Thompson, M.P., Calkin, D.E., 2011. Uncertainty and risk in wildland fire management: a review. Journal of Environmental Management 92, 1895-1909.

Trigo, R.M., Pereira, J.M.C., Pereira, M.G., Mota, B., Calado, T.J., da Camara, C.C., Santo, F.E., 2006. Atmospheric conditions associated with the exceptional fire season of 2003 in Portugal. International Journal of Climatology 26, 1741-1757.

Trigo, R.M., Sousa, P.M., Pereira, M.G., Rasilla, D., Gouveia, C.M., 2013. Modelling wildfire activity in Iberia with different atmospheric circulation weather types. International Journal of Climatology, in press.

Uppala, S.M., Kållberg, P., Simmons, A., Andrae, U., Bechtold, V., Fiorino, M., Gibson, J., Haseler, J., Hernandez, A., Kelly, G., 2005. The ERA - 40 re - analysis. Quarterly Journal of the Royal Meteorological Society 131, 2961-3012.

van Wagner, C.E., 1977. Conditions for the start and spread of crownfire. Canadian Journal of Forest Research 7, 23-24.

Veraverbeke, S., Sedano, F., Hook, S.J., Randerson, J.T., Jin, Y., Rogers, B.M., 2014. Mapping the daily progression of large wildland fires using MODIS active fire data. International Journal of Wildland Fire 23, 655-667.

Yebra, M., Dennison, P.E., Chuvieco, E., Riaño, D., Zylstra, P., Hunt, E.R., Danson, F.M., Qi, Y., 
Jurdao, S., 2013. A global review of remote sensing of live fuel moisture content for fire danger assessment: Moving towards operational products. Remote Sensing of Environment 136, 455468.

\section{Web References}

SNIRH, http://snirh.apambiente.pt/, accessed at 5 of January, 2015.

ICNF, http://www.icnf.pt/portal/florestas/dfci/cartografia-dfci, accessed at 5 of May, 2015. 